\title{
Effect of Wind-Induced Internal Pressure on Local Frame Forces of Low-Rise Buildings
}

\author{
Filmon Habte ${ }^{1}$, Arindam Gan Chowdhury*2, and Ioannis Zisis ${ }^{2}$ \\ ${ }^{1}$ Karen Clark and Company, Boston, MA, USA \\ ${ }^{2}$ Department of Civil and Env. Eng., Florida International University, Miami, FL, USA \\ * Corresponding Author \\ fhabte@karenclarkandco.com, chowdhur@fiu.edu, izisis@ fiu.edu
}

\section{Abstract}

Given the significant role of internal pressures in the wind-induced loading of low-rise buildings, their correct estimation is critical for the accurate determination of the net (external plus internal) wind effects. This paper presents results of an investigation conducted to study the effect of windinduced internal pressures on structural frame forces on low-rise buildings with single or multiple dominant openings. Models from the National Institute of Standards and Technology (NIST) aerodynamic database with internal pressure measurements were used. Large-scale experiments were also conducted in the Wall of Wind (WOW) facility at Florida International University (FIU) using a model with multiple openings. Calculations of frame forces were performed using the DatabaseAssisted Design (DAD) methodology. It was found that internal pressure significantly increases the forces induced by wind with the most unfavorable direction on the frames located close to the openings. However, its effect on the frames located away from the openings was smaller. Effects of internal pressure also varied between different cross-sectional locations of the same frame, depending upon the correlation between forces induced by external and internal pressures. For the highest net frame forces, the reduction factor applied to the response induced by internal pressures, that accounts for the imperfect correlation between the external and internal pressures, was found to be approximately 0.85 . Comparison between frame forces calculated using experimentally measured internal pressures and their counterparts evaluated by using ASCE 7-10 provisions for internal pressures showed that the latter result in unconservative estimates of frame forces in both enclosed and partially enclosed buildings. An additional significant result is that the ASCE 7 classification of buildings with equally sized windward and leeward openings as enclosed buildings can lead to the 
underestimation of net frame responses. It is therefore proposed that this classification be changed to

31 reflect the appropriate internal pressure effects.

32 Keywords: Wind Loading; Internal Pressure; Frame Forces; Large-Scale Experiment; DatabaseAssisted Design; ASCE 7; Wall of Wind

\section{Introduction}

The design of buildings for wind should account for the possible increase of the wind loading due to failures of unprotected windows and/or doors. The characteristics of wind-induced internal pressures are affected by the size, geometry and location of the openings, the volume, shape and envelope flexibility of the building structure, and the characteristics of the external wind pressure. An opening on the windward side can induce high positive internal pressures, which when combined with negative external pressures on the roof might produce high net pressures that can lead to building failures. This is a particularly common scenario in severe events such as tropical cyclones and hurricanes, during which openings can be breached by windborne debris or by direct wind loading [1]. The importance of understanding the effects of wind-induced internal pressures on low-rise buildings is widely recognized and has been the subject of extensive research. However, difficulties associated with model scaling requirements needed for the correct measurement of internal pressures in wind tunnels have limited the amount of reliable experimental data available.

Most previous research on internal pressure has dealt with understanding the characteristics of internal pressures under various opening configurations. However, in design, it is not only the internal pressures themselves that are important; what matters from a design viewpoint is the net loading induced by the combination of internal and external pressures. Net fluctuating pressures/responses are highly affected by the correlation between the fluctuating internal and external pressures, and between the respective responses they induce: higher correlation coefficients entail higher net pressure peaks. Internal pressure loading may contribute a high proportion of the total wind loading for both major structural elements and for cladding of low-rise buildings [2]. Some researchers ([3]; [4]; [5]; [6]) have studied the nature of net wind-induced loads on cladding of low-rise buildings for which high 
correlations between external and internal pressures were observed. Wind loads on cladding are determined by the pressure distribution within a relatively small surface area. However, wind-induced forces on structural systems, for example frames, are affected by the correlation of the external and internal pressures in the entire area tributary to the system.

60 The scope of the few available studies of the internal pressure effects on low-rise building Main Wind Force Resisting Systems (MWFRS) is limited. This paper therefore presents results of a comprehensive study of this topic. According to Holmes and Ginger [1], if the size of an opening is greater than approximately twice the total background leakage area, the opening can be considered as dominant. Typically, the single dominant opening on the windward side is the case usually considered critical in design. However, the accurate evaluation of internal pressures in buildings with single or multiple openings can be warranted as well ([7]; [8]). Hence, this study also included multiple opening cases.

The structures considered in this study are low-rise industrial buildings characterized by rectangular shapes, gable roofs with no overhangs, no ceilings or wall partitions, and a structural system composed of equally spaced moment resisting steel frames. Data on internal pressures available in the National Institute of Standards and Technology (NIST) aerodynamic database (www.nist.gov/wind) were used to represent models with single dominant openings. In addition, large-scale testing was conducted at the Florida International University's (FIU) Wall of Wind (WOW) facility to measure wind-induced internal and external pressure on a low-rise building model with multiple dominant openings. Time histories of wind-induced frame forces were evaluated from time-histories of experimentally recorded pressures using Database-Assisted Design (DAD) methodology [9]. DAD is a computer-intensive, user-friendly automated design procedure that can be used for evaluating the time histories of frame responses from time-histories of internal, external and net wind pressures recorded on large number of pressure taps.

This study also presents a thorough comparison between wind forces computed using experimentally measured internal pressures on the one hand and based on Minimum Design Loads for 
82 Building and Other Structures [10] provisions on the other. Furthermore, instead of comparing the 83 experimentally recorded internal pressures to those recommended by ASCE 7-10, as was done in most 84 previous studies, this work focuses on the effective influence of internal pressures on the net windinduced force. The results of this research can assist in developing improved code provisions on windinduced internal pressures.

87 Section 2 provides a brief description of the experimental data used in this study. In Section 3, the effect of internal pressures on net frame forces is investigated. Section 4 presents a comprehensive comparison of frame forces computed using experimentally recorded internal pressures to those estimated using ASCE 7-10 provisions. Finally, conclusions are provided in Section 5.

\section{Experimental Data}

This study used data from the NIST public aerodynamic database, and from experiments conducted at FIU's WOW facility. Two models from the NIST database (referred to as the NIST model 1 and NIST model 2) were used to study the effects of internal pressures on frame forces in low-rise buildings with single dominant openings. Since internal pressure measurements in the NIST database are limited to models with single dominant opening, a large-scale experimental testing was conducted at the WOW using a model with multiple dominant openings (referred to as the WOW Model). A third model from the NIST database (referred to as the NIST Model 3), with full-scale dimensions identical to the WOW model, was used to compare results computed using the NIST database with those evaluated experimentally at the WOW, for a no-opening case. Table 1 provides summary of the experimental data used for the different analyses. 


\begin{tabular}{|c|c|c|c|c|c|}
\hline \multirow{2}{*}{ Model } & \multicolumn{2}{|c|}{ Prototype Dimensions (m) } & \multirow{2}{*}{$\begin{array}{c}\text { Roof } \\
\text { slope }\end{array}$} & $\begin{array}{c}\text { Length } \\
\text { Scale }\end{array}$ \\
\cline { 2 - 4 } & Width & Length & Height & $1: 12$ & $1: 100$ \\
\hline NIST Model 1 & 24.4 & 38.1 & 12.2 & $1: 12$ & $1: 100$ \\
\hline NIST Model 2 & 24.4 & 38.1 & 4.9 & $1: 12$ & $1: 100$ \\
\hline NIST Model 3 & 12.2 & 19 & 3.66 & $1: 12$ & $1: 8$ \\
\hline WOW Model & 12.2 & 19 & 3.66 & 12 \\
\hline
\end{tabular}

Type of Analysis

${ }^{a}$ Frame forces for case of single dominant opening

${ }^{\mathrm{b}}$ Comparison of results based on NIST and WOW data - no opening case

${ }^{\mathrm{c}}$ Frame forces for case of multiple dominant openings

110 The following subsections provide descriptions of the NIST and WOW experimental data.

\section{$2.1 \quad$ NIST Dataset}

112 The NIST public aerodynamic database covers building configurations characterized by 113 rectangular shape in plan, gable roof, and no overhang. The total number of buildings with distinct 114 dimensions and roof slopes covered by the database is 37 , and all the models were tested in both open 115 and suburban terrain for 39 wind directions at 5 deg increments. However, of those 37 models, 116 internal pressure measurements were conducted on only two models, both of which have a dominant 117 opening.

118 NIST models 1 and 2 that include internal pressure measurements have identical dimensions 119 except for their eave heights. The models have equivalent full-scale width $\mathrm{W}=24.4 \mathrm{~m}$ and length $\mathrm{L}=$ $12038.1 \mathrm{~m}$, with a roof slope $\theta=1: 12$. The first model, henceforth referred to as NIST Model 1 has eave 121 height $\mathrm{H}=12.2 \mathrm{~m}$, and the second model, henceforth referred to as NIST Model 2 has eave height $\mathrm{H}$ $122=4.9 \mathrm{~m}$. These models, which were tested at the University of Western Ontario (UWO) [7], were constructed of acrylic glass at a scale of 1:100. Each model had a large opening representing $3.3 \%$ of 

uniform background leakage (provided by eighty holes of $1.6 \mathrm{~mm}$ diameter at model scale). In this study, only the large openings were used, and during testing, the openings for the background leakage remained open [7].

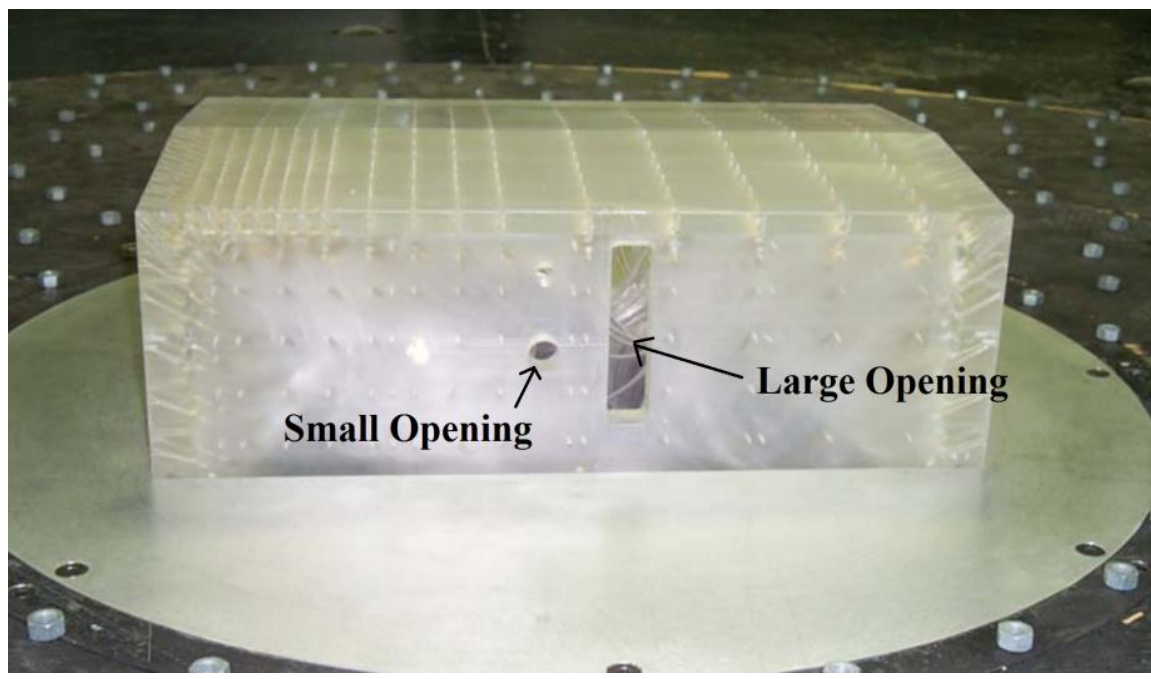

Figure 1 Orientation of Large and Small Openings in the NIST Model

Wind-induced pressure measurements were conducted at the UWO boundary layer wind tunnel for equivalent full scale time duration of $3600 \mathrm{~s}$, at a velocity scaling of 1:4. During experimental investigations of internal pressure fluctuations in a micro-meteorological laboratory (wind tunnel or open jet facility), if a scaled down wind velocity is used, which is true in most cases, additional volume should be incorporated into the building model ([11];[12]). This is required in order to scale correctly the frequencies of the internal pressure fluctuations to those associated with the external pressures. To satisfy this requirement additional volume was added underneath the UWO wind tunnel [13]. Internal pressures were measured simultaneously at two locations within the model (using 30inch long tubing systems to connect the pressure taps to solid state high speed pressure scanners, at a sampling frequency of $500 \mathrm{~Hz}$ for a period of $100 \mathrm{~s}$. Detailed information on the test models, UWO wind tunnel characteristics, and test protocols can be found in Ho et al. ([13];[14]).

NIST model 3 had no building openings and was used to compare results computed using the NIST database with those evaluated experimentally at the WOW. 


\subsection{Wall of Wind (WOW) Test Data}

The WOW (Figure 2) is an open jet facility capable of producing hurricane strength wind speeds. It has 12 electric fans arranged in a two row by six-column pattern, which produces a wind field $6 \mathrm{~m}$ wide and $4.3 \mathrm{~m}$ high, allowing aerodynamic testing of large-scale models or full-scale portions of small buildings.

a.

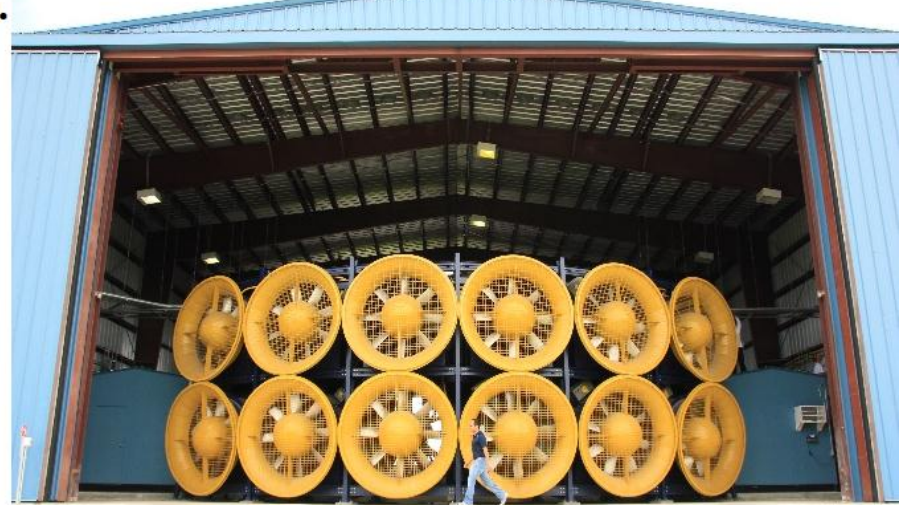

b.

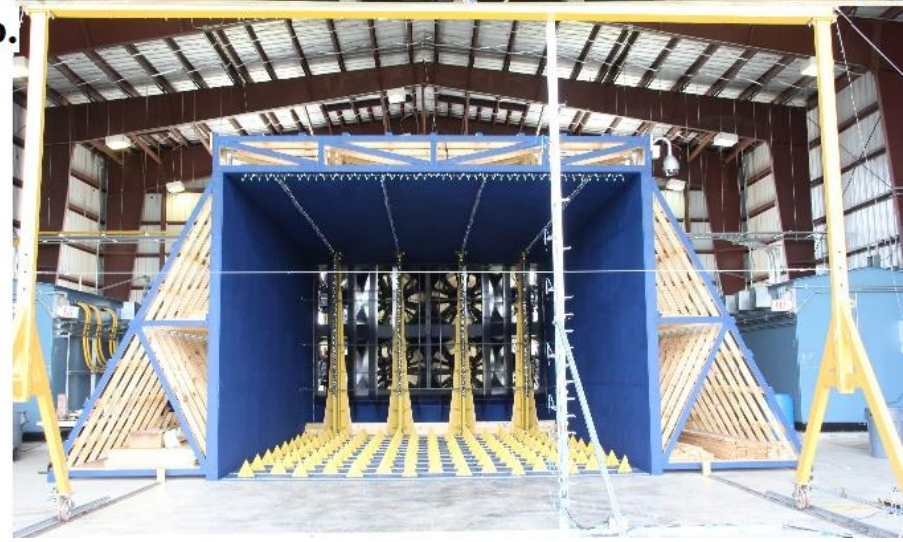

Figure 2 Wall of Wind (WOW) facility side at Florida International University (FIU), a. Intake side and $b$. Outlet side

Figure 3 shows WOW simulated open country conditions mean wind speed profile (with target

ABL of $\alpha=1 / 6.5$ ), turbulence intensity profile, and content of the WOW generated turbulence spectrum (at eave height of the 1:8 model used for this study) and its comparison with the Kaimal spectrum. The Kaimal spectrum shown in Figure 3 is generated using a full-scale roughness length $z_{0}$ $=0.03 \mathrm{~m}$ (the typical roughness length of an open terrain exposure, as listed in the Commentary to ASCE 7-10, p. 540). It can be seen from Figure 3 that the WOW tests were conducted in turbulence in 
which only the higher-frequency components of a typical Atmospheric Boundary Layer (ABL) have been correctly simulated, i.e. in a so-called "Partial Turbulence Spectrum." Such partial turbulence simulations are common in large scale tests as the limited size of the wind facilities hinders the simulation of the low-frequency turbulence and only the higher frequency end of the turbulence spectrum can be simulated ([15]; [16]; [17]). Simulation of the higher frequency fluctuations has been noted by a number of previous researchers as necessary for correct simulation of local flow aerodynamics ([18]; [16]; [17]; [19]; [20]). Asghari Mooneghi et al. [21] have shown that the effects of the missing low-frequency fluctuations can be included in post-test analysis to produce accurate estimates of peak wind-induced pressures/loads.

a.

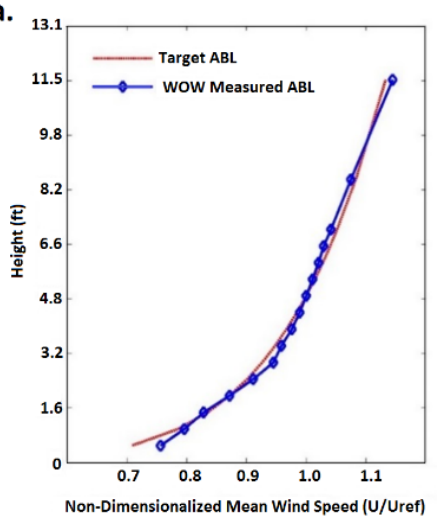

b.

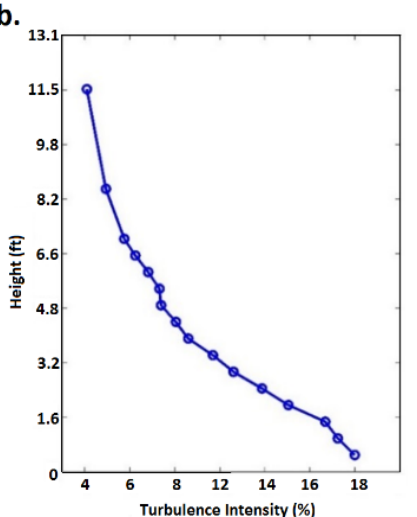

c.

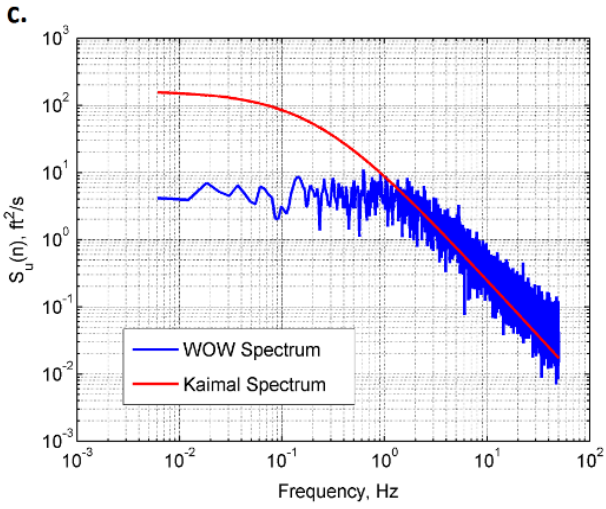

Figure 3 Simulation of open terrain ABL in the WOW: a) mean wind speed profile, b) turbulence intensity profile, and c) turbulence spectrum

The model used for the WOW testing was a 1:8 scale model of a low-rise gable building having a geometric configuration similar to the NIST models. The prototype building dimensions were $\mathrm{W}=12.2$ $\mathrm{m}, \mathrm{L}=19 \mathrm{~m}, \mathrm{H}=3.66 \mathrm{~m}$, and $\theta=1 / 12$ (Figure 4). The model was fabricated using double layer acrylic glass with a total wall thickness of $152 \mathrm{~mm}$ (at full scale). This enabled the accurate scaling of the wall opening thickness, which is important for the correct simulation of the internal pressure, particularly for small openings [22]. The model had a total of 17 openings (representing unprotected doors and windows) distributed on its four walls (Figure 4). It also had background porosity (leakage) of $0.01 \%$ of the entire wall area (as suggested in Ginger et al. [23]), simulated using uniformly distributed holes on the model walls. In the WOW testing, by using a large-scale model $(1: 8$ as 

was avoided [24]
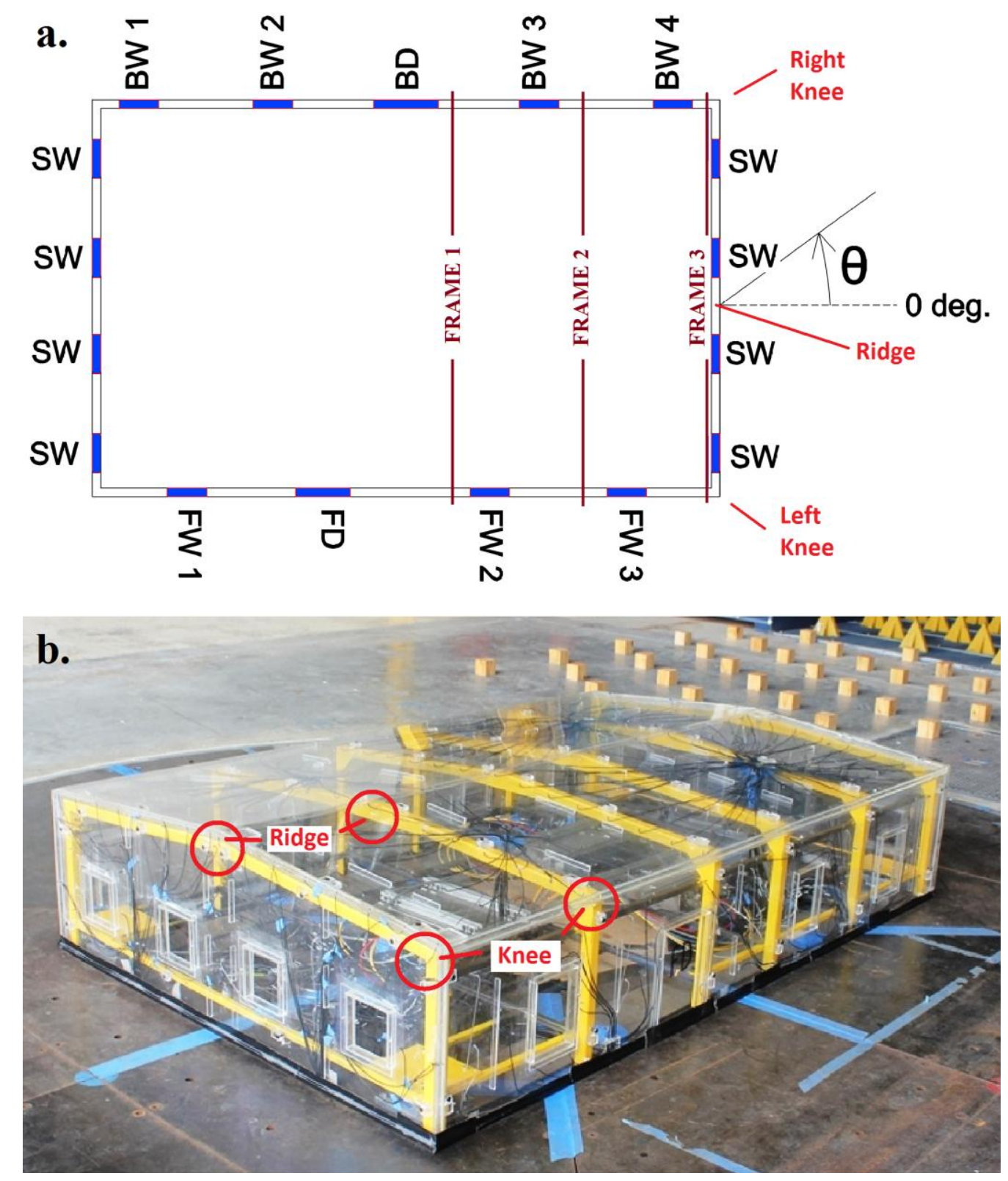
of internal taps were used to capture any possible internal pressure non-uniformities that might exist,

opposed to 1:100) and assuming a velocity scale of unity, the internal volume distortion requirement

Figure 4 Large-Scale Model used in Experimental Investigation: a. Layout and b. Actual Model

The experiments were conducted for 8 wind directions (i.e., $0^{\circ}$ to $315^{\circ}$ at $45^{\circ}$ increments). The test model was instrumented with 286 external pressure taps and 57 internal pressure taps. Large numbers as has been observed by previous researchers in buildings with multiple dominant openings ([8]; [25]). Time-histories of wind pressures were collected using $6.35 \mathrm{~mm}$ ID polyurethane pressure tubes 
and Scanivalve pressure scanning system. Pressure data were collected at a sampling rate of $520 \mathrm{~Hz}$.

189 A tubing transfer function [26] was developed and necessary corrections for pressure tubing length 190 were performed.

\section{Effect of Internal Pressure on Frame Forces}

Internal pressures are relatively uniform as compared to external pressures that can be highly nonuniform in space. As a result, the effects of internal pressures on structural forces can sometimes be significantly higher than the effects of external pressures. Note that the non-uniformity of the external pressure causes the induced peak forces to decrease as the effective area being considered increases. This is particularly important in the design of the main structural components, such as frames, rather than in the design of components and cladding, which are typically controlled by pressure loads on relatively smaller areas. This section presents results of an investigation into the characteristics of net frame forces in buildings with single and multiple openings.

\subsection{Structural Configuration of the Building Models}

The buildings considered in this study are assumed to have a structural system consisting of equally spaced moment-resisting steel portal frames with web-tapered members spanning the width of the building. Roof and wall panels, connected to the frames using purlins/girts, form the exterior envelope of the buildings. The models have no false ceiling, and the internal space is assumed to have no partitions.

The following assumptions are made in transferring wind loading from the roof and wall panels to the structural members: (1) bracing is provided in the planes of the exterior walls parallel to the ridge, hence responses to loads in that direction are not considered, (2) the coupling between frames due to the roof diaphragms is neglected, and (3) the purlins and girts are attached to the frames by hinges,

210 hence no moment load is transferred.

\subsection{Method for Determining Frame Forces, Database-Assisted Design (DAD)}

212 Database-Assisted Design (DAD) is a computer-intensive, user-friendly automated design 213 procedure that can be used for evaluating time-histories of frame responses from time-histories of 
internal, external or net wind pressures recorded on large number of pressure taps. DAD has the advantage of maintaining the synchrony of the pressures measured at a large number of taps, both external and internal. This results is highly accurate estimates of wind induced frame responses. Previous research has shown that DAD has the potential of achieving designs of buildings subjected to wind action that are more consistent with respect to risk than designs based on conventional standard provisions ([27]; [28]; [29]; [30]). Since its conception the DAD methodology has been successfully used to estimate wind responses in low and high-rise buildings. It has also been used to: determine wind effects on wood frame buildings [31], estimate wind directionality factors $\left(K_{d}\right)$ in hurricane prone and non-hurricane prone regions [32], and produce risk-consistent designs of frames using time histories of their demand-to-capacity indexes [33]. In this study, the DAD based windPRESSURE software package [9] was used to compute the wind induced frame responses. However, since the windPRESSURE software can be used with time-histories of external pressure only, it was modified to accommodate internal pressures data (internal pressures either measured in wind tunnels as time-histories or estimated based on code provided internal pressure coefficients).

Time histories of the wind-induced frame forces, $r_{i j}(t, \theta)$ at cross section $j$ of frame $i$, due to a unit wind speed at building eave height, for wind direction $\theta$, are computed as

$$
r_{i j}(t, \theta)=1 / 2 \rho \sum_{k=1}^{n} N_{i j}^{k} A_{i}^{k} C_{p}^{k}(t, \theta)
$$

where $\rho$ is air density; $N^{k}{ }_{i j}$ is the influence coefficient representing the internal force at cross section $j$ of frame $i$, due to a unit force applied at the $k$-th point of attachment (i.e. purlin or girt) to the frame $i$; and $A^{k}$ represents the tributary area of the $k$-th attachment point. $C_{p,}^{k}(t, \theta)$ is the time history of pressure coefficient applicable at the $k$-th attachment point, normalized by wind speed at eave height for wind direction $\theta$; and $n$ is the number attachment points on frame $i$. Time histories of net pressure coefficients, $C_{p, \text { net }}(t, \theta)$ are computed from time histories of external and internal pressures as follows.

$$
C_{p, \text { net }}(t, \theta)=C_{p, \text { ext }}(t, \theta)-C_{p, \text { int }}(t, \theta)
$$

The net wind-induced responses are evaluated using the net pressure coefficients, $C_{p \text {, net }}^{k}(t, \theta)$ in place of $C_{p,}^{k}(t, \theta)$ in Eq. (1). Individual external and internal responses can be also estimated by using 
external pressure coefficients, $C_{p \text {, ext }}^{k}(t, \theta)$ and internal pressure coefficients, $C_{p, \text { int }}^{k}(t, \theta)$, respectively, 241 in place of $C_{p,}^{k}(t, \theta)$ in Eq. (1).

242 Once the time histories of frame forces are evaluated, the peaks can be computed using peak estimation methods (the peak estimation methods used are described in the subsequent sections). In this study, the frame responses selected for investigation are bending moments at the left knee, ridge and right knee of the building frames being considered (Figure 4). Peak moment coefficients, $\hat{C}_{m}$, are obtained from peak frame bending moments $\hat{m}$ induced by unit wind speed at eave height, as follows:

$$
\hat{C}_{m}=\frac{\hat{m}}{1 / 2 \rho \cdot W \cdot H \cdot f_{S}}
$$

where $f_{s}$ denotes frame spacing.

\subsection{Peak Estimation Methods, and Comparison of Results Based on NIST and WOW Data}

For the NIST models, once the time histories of frame moments were computed using Eq. (1), peak moments were evaluated using the translational non-Gaussian peak estimation method proposed by Sadek and Simiu [34] (henceforth referred to as the SAS method) and built in the windPRESSURE program [9]. The SAS method follows a translational approach to estimating peaks of time series with non-Gaussian marginal distributions, which are typical for low-rise buildings. In this method, the peaks are first obtained under the assumption that time series have a Gaussian distribution. The peaks are then subjected to non-linear mappings from Gaussian to non-Gaussian distributions. The method uses the information contained in the entire time-history; the estimates are therefore more stable than estimates based on observed peak methods [34].

As mentioned previously the WOW tests were performed in a flow field with partially simulated turbulence, hence the turbulence intensity in the WOW was lower than that of an atmospheric boundary layer $(\mathrm{ABL})$ flow containing the full spectrum of turbulence. This is mainly due to the fact that low frequency turbulence cannot be simulated fully when using full- or large-scale models due to the limited size of the wind testing facilities; only the higher frequency end of the turbulence spectrum is simulated. Hence, the partial turbulence simulation method (henceforth referred to as PTS method) was used for data analysis that accounts for the missing low frequency turbulence. Details of the PTS 
method are given in Asghari Mooneghi et al. [21; 35]. In this method, the turbulence is divided into two distinct statistical processes, one at higher frequencies which can be simulated correctly in the wind tunnel, and one at low frequencies which can be treated in a quasi-steady manner. The joint probability of the load from these two processes is derived, with one part coming from the WOW data and the remainder from the Gaussian behavior of the missing low frequency component. For the evaluation of these estimated values, the peak value with $79 \%$ probability of not being exceeded in one hour of wind with full turbulence spectrum was used.

The translational SAS method of peak estimation was used for the 1:100 NIST/UWO models, while the PTS method was employed for the 1:8 large-scale model tested in the WOW. Hence, providing comparison of peak responses evaluated using the two methods is of interest. For the purpose of comparison, a model from the NIST database (i.e. NIST model 3) with geometry and fullscale dimensions identical to the WOW model's prototype was used. Figure 5 shows comparison of external peak moment coefficients at the left knee of frames 1, 2, and 3 evaluated using the NIST model and the WOW model. Note that NIST model 3 had no openings. The numbering of frames is shown in Figure 4, and frame spacing of $4.25 \mathrm{~m}$ was used. It can be seen that, despite the differences in peak estimation methods fairly comparable values of $\hat{C}_{m}$ were achieved. This increases the confidence in not only on the test data but also on the methods of peak estimations used.
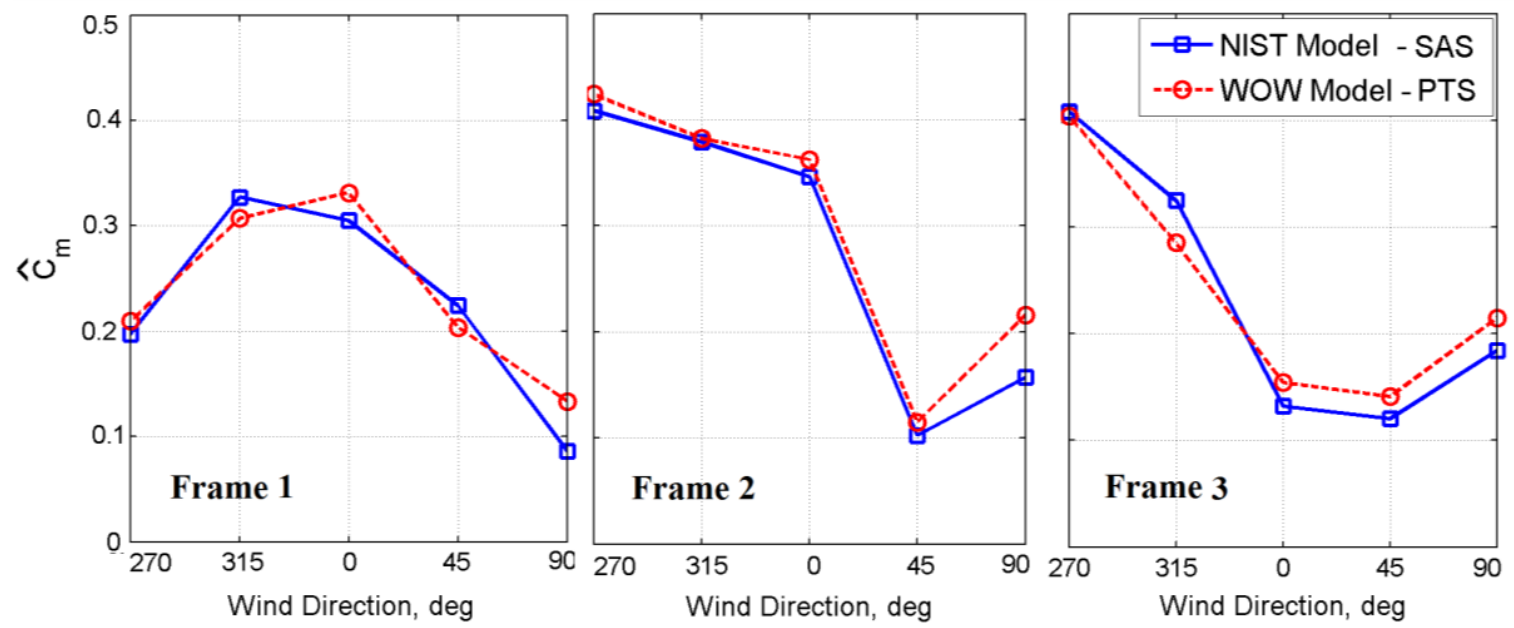

Figure 5 Comparison of $\hat{C}_{m}$ evaluated using the WOW Model and a NIST Model 

velocity compared to the WOW model, which might entail inconsistencies related to differences in Reynolds number. Moreover, there were significant differences in pressure tap densities between the two models, this can have significant influence on test results [36]. Using models with similar tap density and testing scales would have further improved the comparison.

\subsection{Results for Single Dominant Opening}

Comparisons of pressure time-histories between different taps inside the models with single dominant openings showed that the spatial variation of the internal pressure was minimal; hence one internal tap was selected to represent building internal pressure. This was true in both the NIST and WOW models, Figure 6 demonstrates this by comparing time-histories of internal pressure recorded at two different taps in the WOW model. Figure 7 shows the layout of the NIST models 1 and 2 with the frame numbering (frame spacing of $6.1 \mathrm{~m}$ is used), the location of the large opening, and wind direction. Note that the opening shown in Figure 7 is not plotted to scale; it indicates the location of the opening with respect to the frame locations and the wind directions.

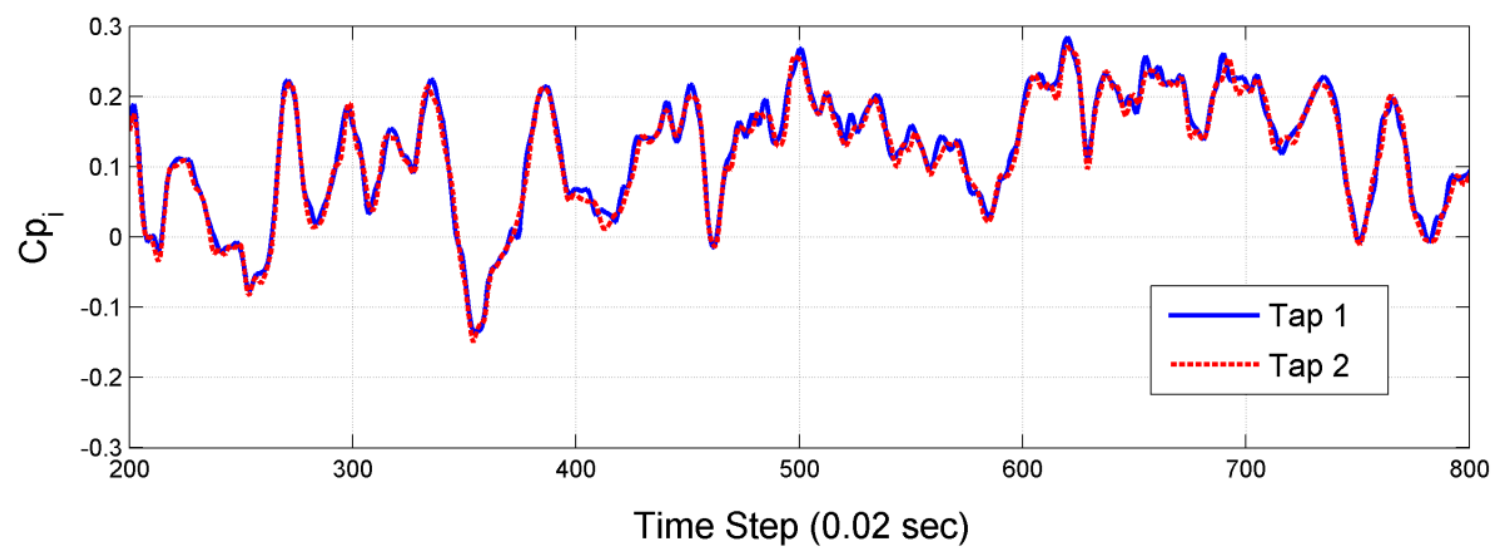




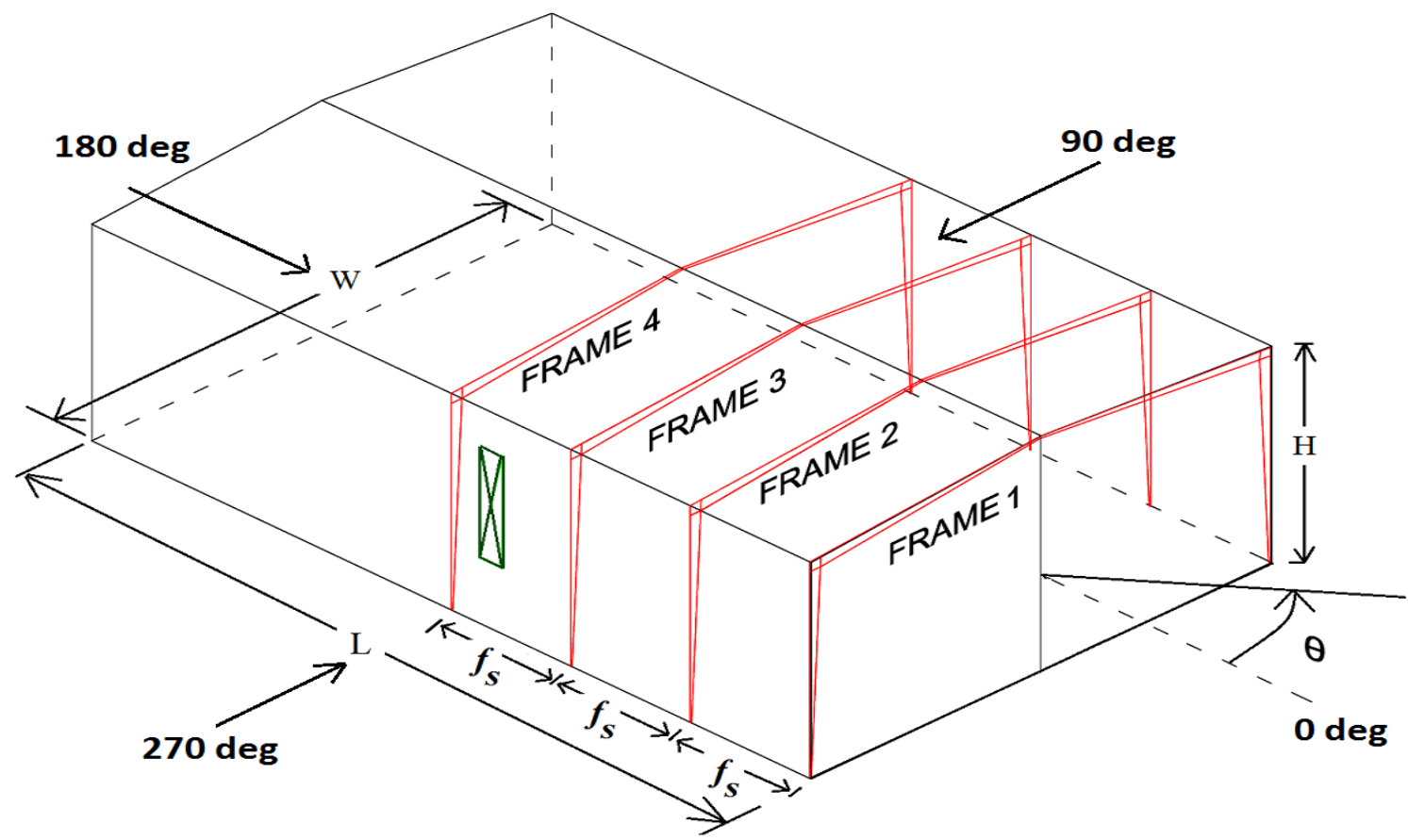

301

302

303

Figure 7 Layout of frames, opening, and wind directions for the NIST models

Figure 8 and Figure 9 show peak moment coefficients at frame 1 and 4, respectively, for NIST model 1, in open terrain exposure. As expected, the effect of internal pressure on the frame forces is highest when the building opening is normal to the approaching wind. Since internal pressure was uniform inside the building, it produced identical moments at the left and right frame knees, however, its effect on the critical (highest of all directions) net frame responses highly varied depending on the location of the frame. For example, in frame 4 (Figure 9), the highest external $\hat{C}_{m}$ for all the cross sections being considered were increased significantly by the presence of an opening. However, for the case of frame 1 (Figure 8), the presence of dominant openings had a minor effect on the critical $\hat{C}_{m}$ 

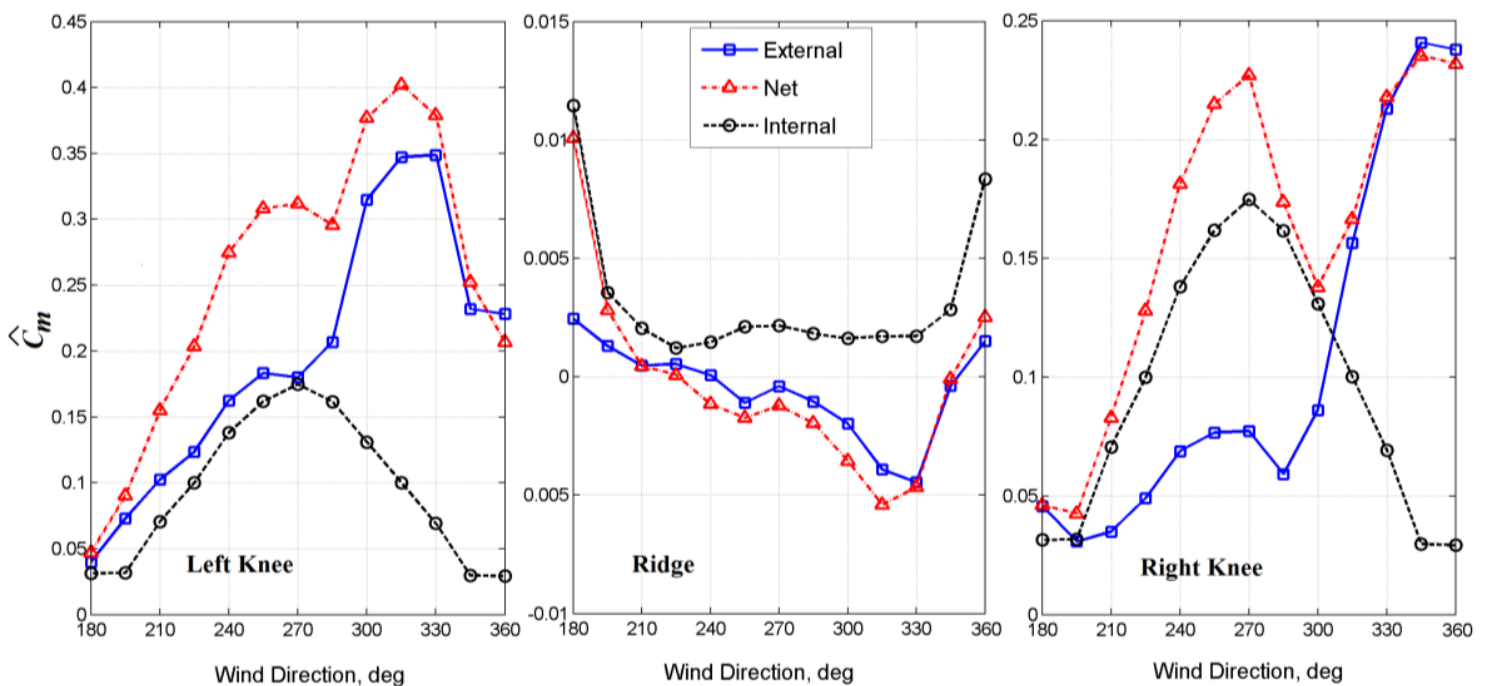

Figure 8 External, Internal and Net Moments, NIST Model 1, Frame 1
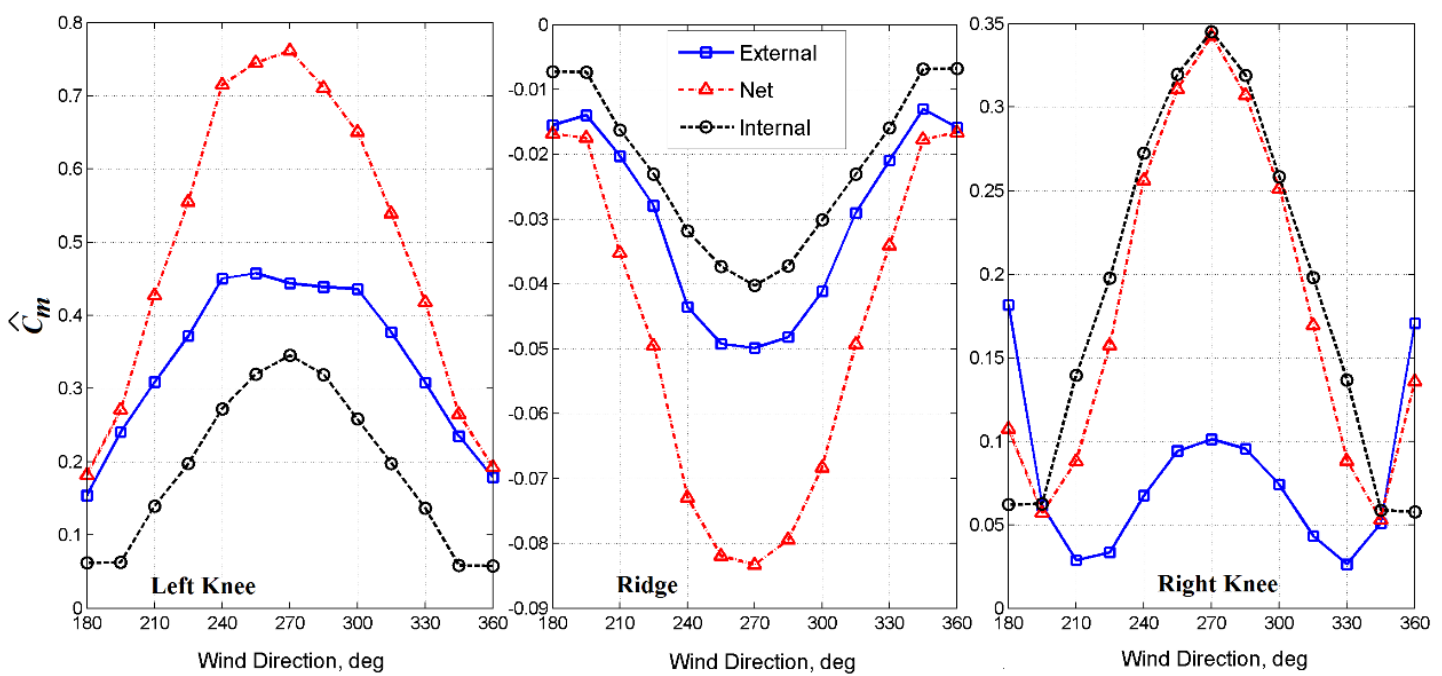

Figure 9 External, Internal and Net Moments, NIST Model 1, Frame 4

The effects of the internal pressure on the net moments varied significantly depending on the correlation between the time histories of the external and internal pressure-induced moments, which differed not only for different frames but also within different locations of the same frame. To investigate this, correlation coefficients, $R_{c}$ between the time-histories of external pressure induced response, $r_{\text {ext }}(t)$ and time-histories of internal pressure induced responses, $r_{i n t}(t)$ were calculated by dividing the cross-correlations (for zero lag-time) by the product of the standard deviations of the two responses, as shown in Eq. (4) 


$$
R_{C}=\frac{\sum_{i=1}^{n}\left(r_{e x t}(t)-\bar{r}_{e x t}\right)\left(r_{\text {int }}(t)-\bar{r}_{\text {int }}\right)}{\sqrt{\sum_{i=1}^{n}\left(r_{\text {ext }}(t)-\bar{r}_{\text {ext }}\right)^{2} \sum_{i=1}^{n}\left(r_{\text {int }}(t)-\bar{r}_{\text {int }}\right)^{2}}}
$$

where $\bar{r}_{e x t}$ and $\bar{r}_{\text {int }}$ denote the mean values for the responses induced by the external and internal wind pressure; and $n$ represents the number of data points in the time-histories. Figure 10 shows correlation coefficients between time histories of moments induced by external and internal pressures on the frames of both NIST model 1 and 2, at various wind directions, for open terrain exposure. The correlation coefficients were observed to vary not only with frame location, but also with crosssection location within the same frame. In general, cross-sections closest to the building openings produced higher correlation coefficients. For example, at 270 deg wind direction, high correlation between the time-histories of moment due to external and internal wind pressure produced very high net $\hat{C}_{m}$ at the left knee of frame 4 . However, the net $\hat{C}_{m}$ at the right knee was almost equal to the $\hat{C}_{m}$ due to internal pressure only; this is due to low correlation between responses induced by the time histories of the internal pressure and external pressures. High positive correlation coefficients, reaching up to 0.67 were observed on frame 4, particularly at wind directions between 225 to $315 \mathrm{deg}$, i.e. when the opening was on the windward side. Correlation coefficients between cladding external and internal pressures of $-0.9,-0.5$ and -0.64 were reported by Mehta et al. [3], Beste and Cermak [4] and Sharma and Richards [6], respectively. Note that the difference in the sign of the highest correlation coefficients between those reported for cladding pressures (e.g. Sharm and Richards [6]) and those presented here for frame forces is due to the fact that internal and external pressures of opposite signs induce frame forces in the same direction. 


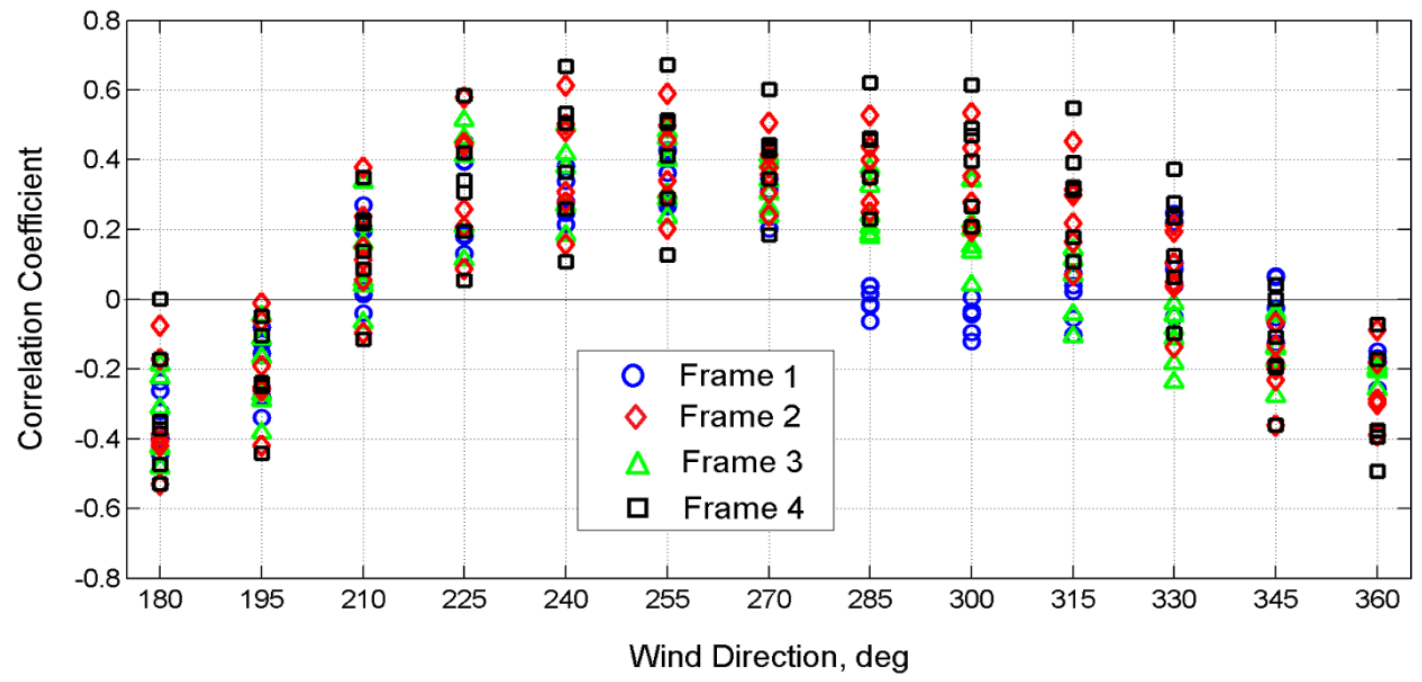

Figure 10 Correlation coefficients, NIST Models 1 and 2, all cross sections

Since internal and external pressure are not perfectly correlated, $\hat{r}_{\text {net }} \neq \hat{r}_{\text {ext }}+\hat{r}_{\text {int. }}$. (where $\hat{r}_{\text {net }}, \hat{r}_{\text {int }}$ and $\hat{r}_{n e t}$ denote peak frame forces induced by external, internal and net pressures respectively, also note that internal and external pressures of opposite signs induce frame forces in the same direction.). Instead, $\hat{r}_{n e t}=\hat{r}_{e x t}+\left(r_{f}\right) \hat{r}_{\text {int, }}$, where $r_{f}$ is a reduction factor included to account for the lack of perfect correlation between the internal and external pressures. Reduction factors, $r_{f}$ for the most critical knee and ridge moments, i.e. the highest moments induced in all frames and for all wind directions (i.e. the directions considered in design), were computed to be 0.85 and 0.83 respectively.

\subsection{Results for Multiple Dominant Openings}

Figure 11 and Figure 12 show peak moment coefficients at frames 1 and 3, respectively, for the WOW model, with FW2 (Front Window 2) and BW3 (Back Window 3) left open. Frame moments induced by internal pressure were highest when the wind direction was normal to one of the openings. At those wind directions, the correlations between moments induced by external and internal pressures were high (Figure 13). This caused the effect of internal pressure on net moments for those directions to be the highest. For frame 3, the critical directions for both the external and internal pressure-induced moments were similar; this resulted in significantly higher design net moments. This was not true for frame 1 , for which the external pressure-induced moments were critical at wind direction of 0 deg (i.e. due to strong wind flow separation at the upwind edge). It can also be seen in 
Figure 12 that internal pressure had alleviating effects (of up to 15\%) on the critical (design) moments experienced by frame 1 . This was due to the predominantly low correlations between the external and internal pressure-induced moments at $0 \mathrm{deg}$ wind direction; see Figure 13, which also shows that correlation coefficients of up to 0.48 were observed.
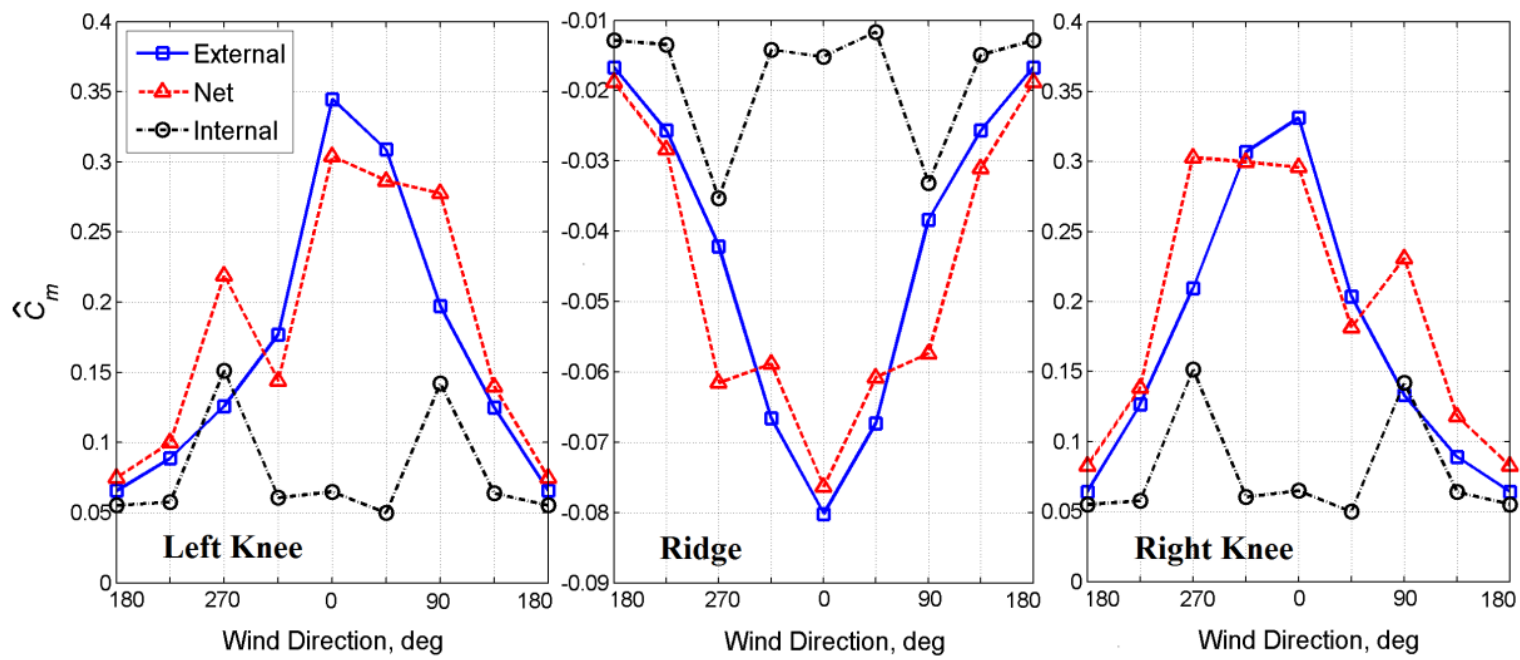

Figure 11 Peak external, internal and net moment coefficients, WOW Model, Frame 1
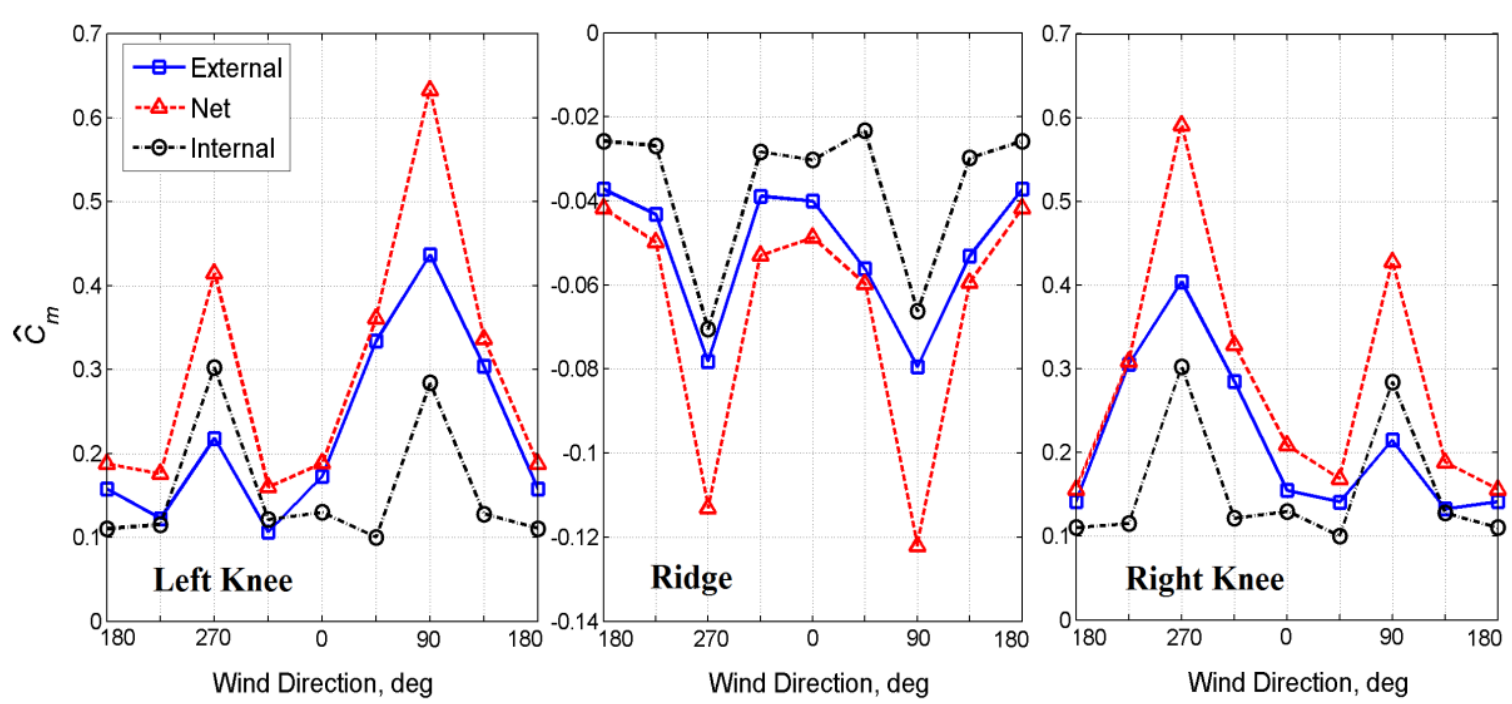

Figure 12 Peak external, internal and net moment coefficients, WOW Model, Frame 3 


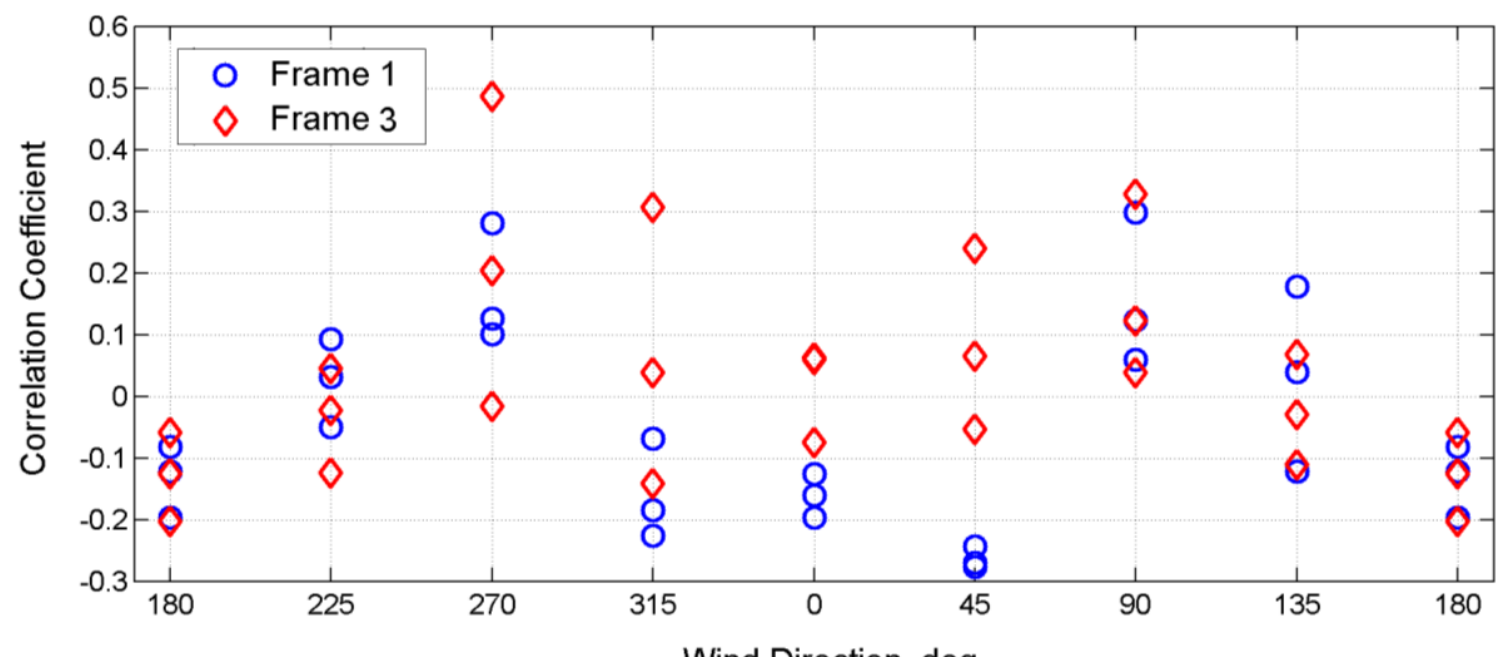

Wind Direction, deg

Figure 13 Correlation coefficients, WOW model, all cross sections

\section{Comparison of Experimental Results with ASCE 7-10 Provision for Internal Pressure}

In this section, the effective contributions of experimentally recorded internal pressures on the net (total) frame forces are quantified, and compared with those evaluated using the ASCE 7-10 provisions for internal pressures. First, a detailed background is provided on the internal pressure recommendations of the ASCE 7-10, and the recommended values of internal pressure for the different building models and the different building opening scenarios. Then comparison of the experimentally computed values with those recommended by the ASCE 7-10 for single opening, cross opening, and multiple progressive openings are provided.

\subsection{ASCE 7-10 Provisions for Internal Pressure - Low-rise Buildings}

The internal wind pressure provisions in the ASCE 7-10 classify buildings into open, partially enclosed and enclosed categories. For an open building, defined as having each wall at least $80 \%$ open, the specified internal pressure coefficient is $G C_{p i}=0$. The highest $G C_{p i}$, which is equal to \pm 0.55 , is specified for partially enclosed buildings. These are buildings which satisfy the following two conditions: (1) The total area of openings in a wall that receives positive external pressure exceeds the sum of the areas of openings in the balance of the building envelope (walls and roof) by more than $10 \%$, and (2) The total area of openings in a wall that receives positive external pressure exceeds 0.37 $\mathrm{m}^{2}$ or $1 \%$ of the area of that wall, whichever is smaller, and the percentage of openings in the balance 
of the building envelope does not exceed $20 \%$. A building that does not comply with the requirements

390 for an open or partially enclosed building is categorized as an enclosed building and $G C_{p i}= \pm 0.18$

391 should be used. If a building complies with both the open and partially enclosed definitions, then it

392 should be considered as an open building. ASCE also recommends that for partially enclosed

393 buildings containing a single, non-partitioned large volume, the $G C_{p i}$ be multiplied by a reduction

394 factor (less than one), which is a function of the ratio of the non-partitioned internal volume to the

395 total area of wall and roof openings.

396 To compare those ASCE 7-10 provided internal pressure values with the experimental results, equivalent pressure coefficients, $G C_{p i \text { eq, }}$, were first calculated using Eq. (5) [37]

$$
G C_{p i e q}=\left(\frac{\frac{1}{2} \rho V_{10 m, 3 s}^{2} K_{z} K_{z t} K_{d}}{\frac{1}{2} \rho V_{H}^{2}}\right) G C_{p i}
$$

where $V_{H}$ is mean wind speed at eave height, $H ; V_{10} \mathrm{~m}, 3 \mathrm{~s}$ is the 3 -s wind speed at $10 \mathrm{~m}$ height; $K_{z}$ is the velocity pressure exposure factor (taken from Table 27.3-1 in ASCE7-10); $K_{z t}$ is the topographic

401 factor (assumed to be one); and $K_{d}$ is the directionality factor (assumed to be one). Table 2 shows responses due to the positive/negative $G C_{p i}$ eq values, $r_{i j, A S C E}$, were then computed as shown in Eq. (6),

404

$$
\left.\begin{array}{l}
r_{i j, A S C E}^{+}=1 / 2 \rho \sum_{k=1}^{n} N_{i j}^{k} A_{i}^{k} G C_{p i, e q}^{+} \\
r_{i j, A S C E}^{-}=1 / 2 \rho \sum_{k=1}^{n} N_{i j}^{k} A_{i}^{k} G C_{p i, e q}^{-}
\end{array}\right\}
$$

Table 2. $G C_{\text {pi eq }}$ for the NIST and WOW models

\begin{tabular}{|c|c|c|c|c|c|c|c|}
\hline \multirow{2}{*}{ Model } & \multirow{2}{*}{$\begin{array}{c}\text { Model } \\
\text { Height } \\
(\mathrm{m})\end{array}$} & $\begin{array}{c}\text { Open } \\
\text { Terrain } \\
\text { Exposure }\end{array}$ & $\begin{array}{l}\text { Suburban } \\
\text { exposure }\end{array}$ & \multicolumn{2}{|c|}{$K_{z}$} & \multicolumn{3}{|c|}{$G C_{p i e q}$} \\
\cline { 5 - 8 } & $\begin{array}{c}\text { Expon Terrain } \\
\text { Partially } \\
\text { Enclosed }\end{array}$ & \multicolumn{2}{|c|}{ Suburban exposure } \\
\hline $\begin{array}{c}\text { NIST } \\
\text { Model 1 }\end{array}$ & 12.2 & 1.04 & 0.76 & \pm 1.24 & - & \pm 1.71 & - \\
\hline
\end{tabular}




\begin{tabular}{|c|c|c|c|c|c|c|c|}
\hline $\begin{array}{c}\text { NIST } \\
\text { Model 2 }\end{array}$ & 4.9 & 0.86 & 0.58 & \pm 1.42 & - & \pm 2.48 & - \\
\hline $\begin{array}{c}\text { WOW } \\
\text { Model }\end{array}$ & 3.66 & 0.85 & - & \pm 1.56 & \pm 0.51 & - & - \\
\hline
\end{tabular}

406

407

The Commentary C26.11 of the ASCE 7-10 states, "the code provided internal pressure coefficients, $G C_{p \text { in }}$ include a reduction factor to account for the lack of perfect correlation between the internal pressure and the external pressures on the building surfaces not containing the opening. Taken in isolation, the internal pressure coefficients can reach values of \pm 0.8 (or possibly even higher on the negative side)." That is, a reduction factor of about $0.55 / 0.8=0.69$ is used (note that this is lower than the experimentally evaluated reduction factor of 0.85 for single dominant openings). Hence, in order to get accurate comparisons, it is not experimentally recorded isolated internal pressures that should be compared (as was done is most previous researches); instead, the effective contributions of internal pressures to the net wind-induced forces need to be determined and compared to those computed using the ASCE 7-10. In this study, the effective contributions of internal pressure were determined by deducting the forces induced by external pressures from those induced by net pressures (estimated from the applied wind pressure). To explain this, let $\hat{F}_{\text {ext }}, \hat{F}_{\text {int }}$ and $\hat{F}_{\text {net }}$ denote peak forces induced on a building by external, internal and net pressure. As noted earlier, $\hat{F}_{n e t} \neq \hat{F}_{\text {ext }}+\hat{F}_{\text {int }}$, instead $\hat{F}_{\text {net }}=\hat{F}_{\text {ext }}+\left(r_{f}\right) \hat{F}_{\text {int, }}$, where $\left(r_{f}\right) \hat{F}_{\text {int }}$ is the effective contribution of the internal pressure to the net wind-induced forces, and can be computed as $\left(r_{f}\right) \hat{F}_{\text {int }}=\hat{F}_{\text {net }}-\hat{F}_{\text {ext }}$. Herein, experimentally computed $\left(r_{f}\right) \hat{F}_{\text {int }}$ were compared with those evaluated using Eq. (6) (i.e. after they are normalized using Eq. (3)).

\subsection{Results for Single Dominant Openings}

According to the ASCE 7-10, low-rise buildings with a single dominant opening considered herein are categorized as partially enclosed buildings. Figure 14 shows the result of such comparison in terms of the ratio of $\hat{C}_{m}$ int to $\hat{C}_{m}$ ASCE for NIST model 1, in both open terrain and suburban exposures. $\hat{C}_{m}$ int represents the peak moment coefficient associated with the effective contribution of the internal 
pressures to the peak net moments, and $\hat{C}_{m}{ }_{A S C E}$ denote moment coefficients corresponding to the $G C_{p i}$

430 eq values shown in Table 2. It can be seen that the ASCE provisions can be highly unconservative for 431 both open terrain and suburban exposures, particularly for the frames close to the building opening.

432 High $\hat{C}_{m \text { int }} / \hat{C}_{m A S C E}$ ratios of up to 1.90 were observed.
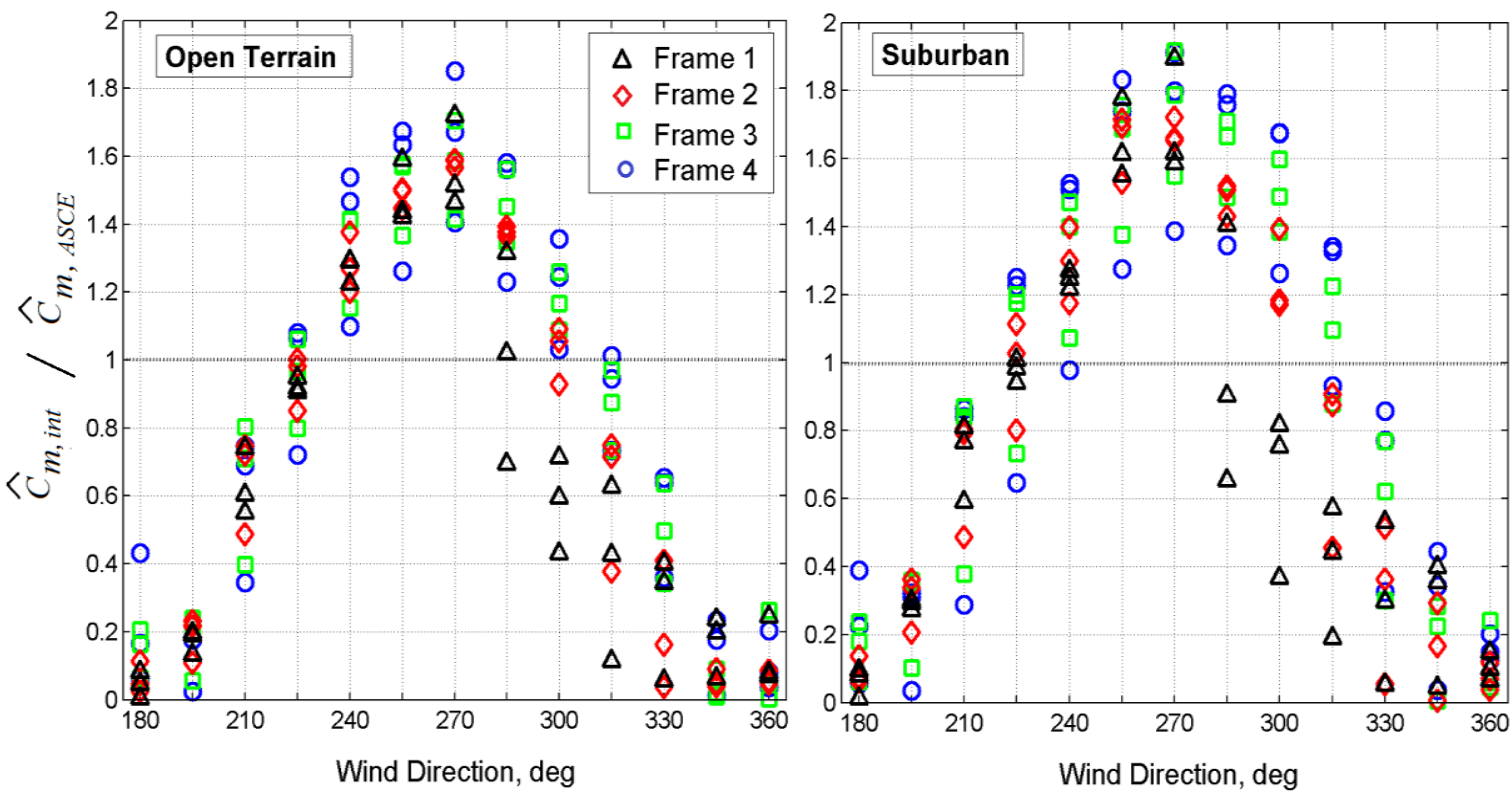

433

434

435

436

437

438

439

440

Figure $14 \hat{C}_{m \text { int }} / \hat{C}_{m}$ ASCE versus wind directions, NIST Model 1

The highest values of $\hat{C}_{m}$ int $/ \hat{C}_{m} A S C E$ observed in Figure 14 occurred at wind directions close to 270 deg (i.e. normal to the building wall containing the opening). Note that these wind directions might not be the critical directions for some frame forces (see Figure 9), and the effects of internal pressure on the critical forces, for such cases, might not be significant. Hence, critical net frame forces evaluated using time-histories of internal wind pressures were compared to those evaluated using $G C_{p i}$ eq. Figure 15 shows results of such comparison for both NIST models 1 and 2, in both open terrain and suburban exposures, and the WOW model (FW2 left open) in open terrain exposure. Note that the points in Figure 15 represent, for each cross-section of all the frames, the largest of the moment coefficients corresponding to all the wind directions considered. In Figure 15a, the critical responses computed using experimental records of internal pressure are compared to those evaluated using the ASCE 7-10 provisions. It can be seen that for several cases the ASCE 7-10 provision produce unconservative results. This is in agreement with numerous previous investigations which 
reached the conclusion that internal pressure provisions in ASCE 7-10 can underestimate the actual

448 internal pressures in partially enclosed low-rise buildings ([7]; [8]; [38]; [39]; [40]). Figure 15b shows

449 a comparison of the critical bending moments to those evaluated using an enveloping $G C_{p i}$ value of $450 \pm 1.0$, and it can be seen that it produces conservative results.

451 a.

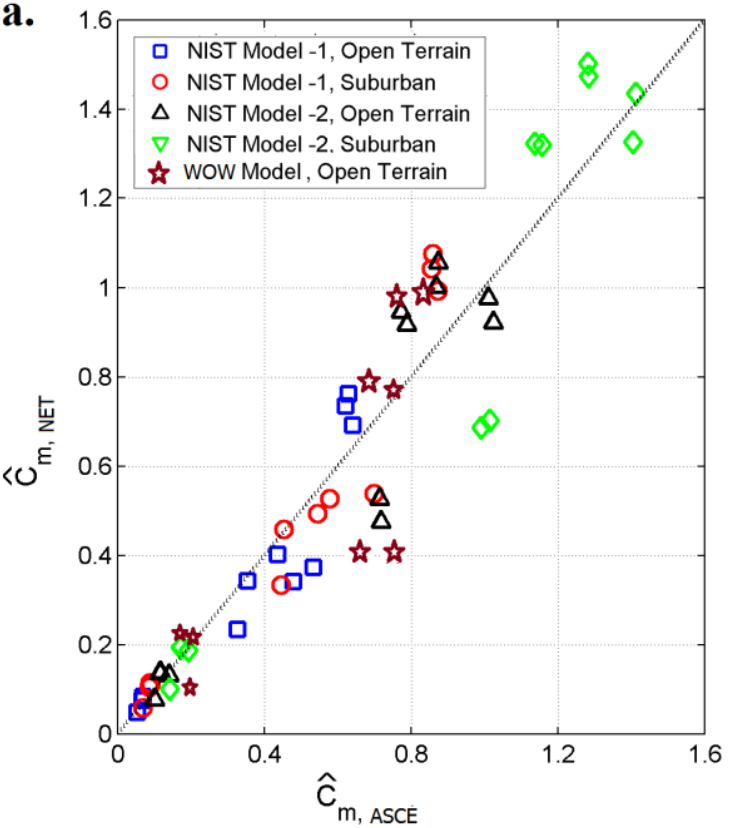

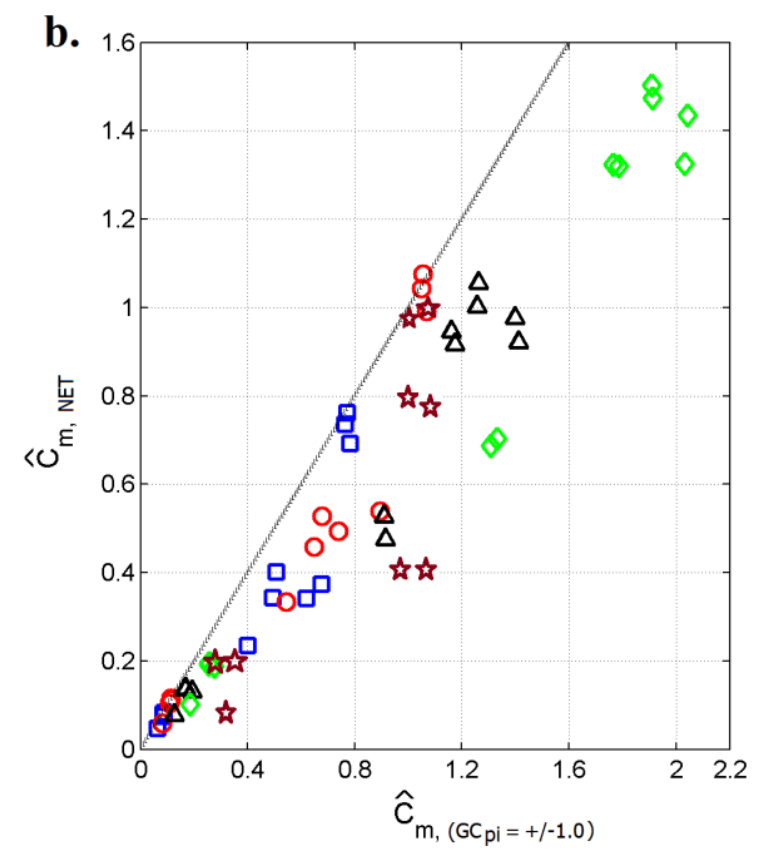

b.

Figure 15 Experimental Computed $\hat{C}_{m}$ versus: a. $\hat{C}_{m}{ }_{A S C E}$ and b. $\hat{C}_{m(\mathrm{GCpi}= \pm 1.0)}$

\subsection{Results for Multiple Dominant Openings}

According to the ASCE 7-10, low-rise buildings with dominant openings of equal sizes on opposite walls are categorized as enclosed buildings, and $G C_{p i}$ values of \pm 0.18 (which corresponds to a $G C_{p i ~ e q}$ of \pm 0.51 for the WOW model height) are recommended for use. Similar to the comparison conducted for the models with single dominant openings, moments evaluated using Eq. (6) were compared to the those associated with the effective contribution of the internal pressures to the net moments, $\hat{C}_{m}$ int. Figure 16 shows results of such comparison in terms of ratio of $\hat{C}_{m}$ int to $\hat{C}_{m}{ }_{A S C E}$ for the case where FW2 and BW3 were left open. 


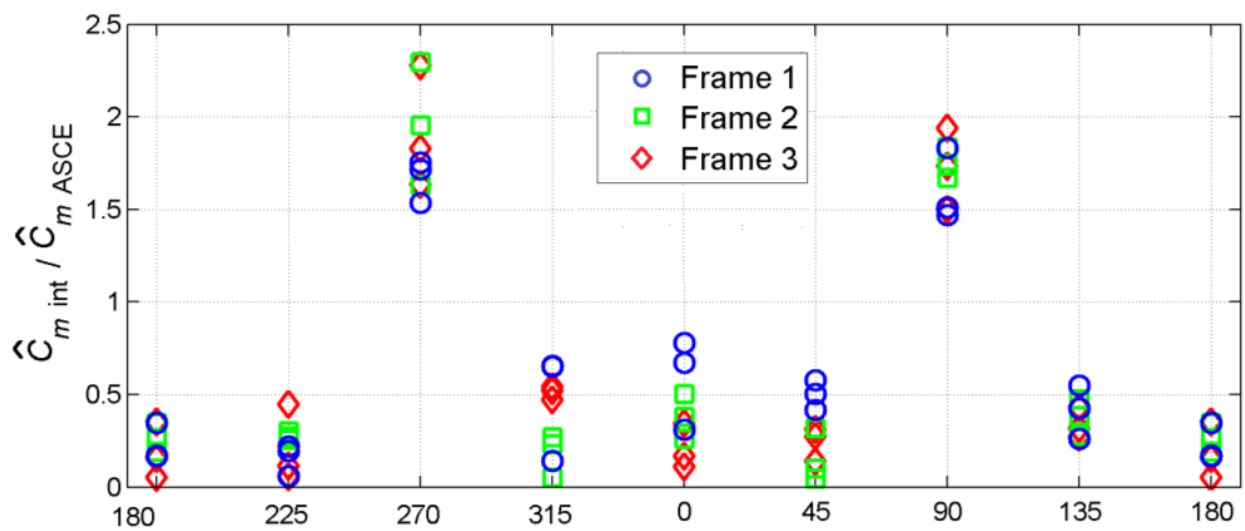

461

462

463

464

465

466

467

468

469

470

471

Figure $16 \hat{C}_{m \text { int }} / \hat{C}_{m}$ ASCE versus wind directions, WOW model (FW2 and BW3)

Figure 17 shows results of comparisons between critical peak net moment coefficients computed using internal pressures from experimental measurements to those evaluated using ASCE 7-10 provisions, for two cases of multiple dominant openings (i.e. BW2 with FW3, and FD with BD). It can be seen that for several cases the ASCE 7-10 provision produced unconservative results, particularly for the case of openings BW2 with FW3. Most importantly, the results show that classifying buildings with equally sized openings on opposite walls as "enclosed buildings," based on the ASCE 7-10 provisions, can result in unconservative estimates of internal pressure-induced frame forces. Figure $17 \mathrm{~b}$ shows that using an enveloping value of \pm 0.42 produced in most cases moderately conservative results.
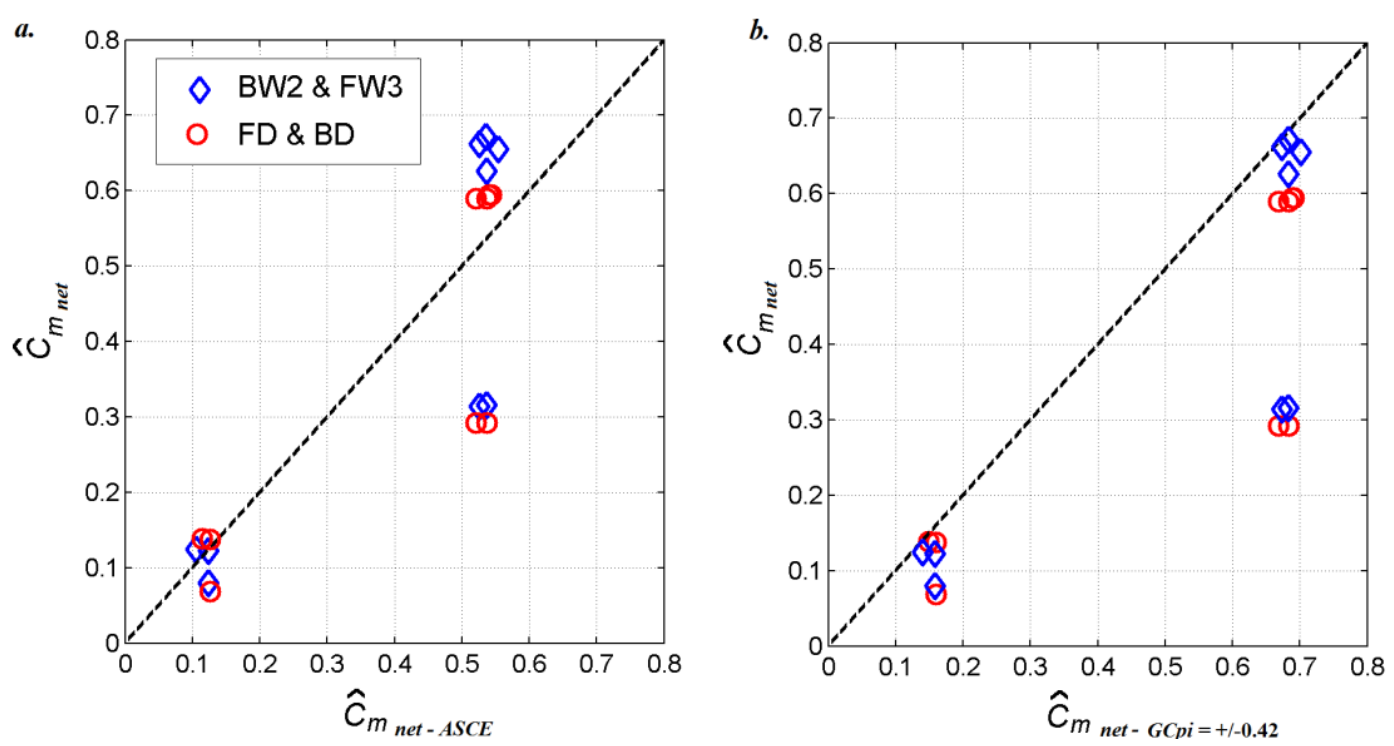

Figure 17 Experimental Computed $\hat{C}_{m}$ versus: a. $\hat{C}_{m}{ }_{A S C E}$ and b. $\hat{C}_{m(\mathrm{GCpi}= \pm 0.42) \text {, WOW Model }}$ 


\subsection{Results for Progressive Opening Failure}

To further investigate the effect of multiple building openings on frame forces, and understand how internal pressure evolves during a progressive failure of building openings, which might occur during hurricanes, an experiment was conducted where several openings failures were progressively simulated. Note that in hurricanes strong winds, wind-borne missiles can occur from more than one direction during a storm, and that this is also possible in other types of storm, e.g., thunderstorm and tornadoes. This experiment included 11 test cases (at wind direction of $270 \mathrm{deg}$ ) in which openings failures were simulated sequentially in the following order; FW 2, FW 3, FW 1, FD, BD, BW 2, BW 3, BW 1, BW 4, SW 1 - SW 4 and SW 5 - SW 8. Once an opening was created, it remained open for the rest of the test. That is, in test case 1, only FW2 was left open and testing was conducted at 270 deg wind direction, then in test case 2, both FW2 and FW3 were left open and testing was conducted at the same wind direction, and so on until test case 11 where all the model doors and windows were left open. The front windows (FW) and back windows (BW) had full-scale sizes of $1.62 \mathrm{~m}^{2}$ each, the side windows (SW) had an area of $1.14 \mathrm{~m}^{2}$ each, and the doors (FD and BD) had an area of $3.72 \mathrm{~m}^{2}$ each.

According to the ASCE's definition of building enclosure, for the no opening test case the model is categorized as an enclosed building. In the progressive failure of openings test, the model becomes partially enclosed when the first dominant opening is created. The model then transitions back to enclosed building at test case 8 (openings: FW 2, FW 3, FW 1, FD, BD, BW 2, BW 3, BW 1). Figure 18 shows the effective contribution of internal pressures to net bending moments evaluated during the progressive opening experiments, and compares them with peak moment coefficients evaluated using the ASCE 7-10 provisions for internal pressure. It can be seen that as more openings were created the peak moment coefficient decreased. 

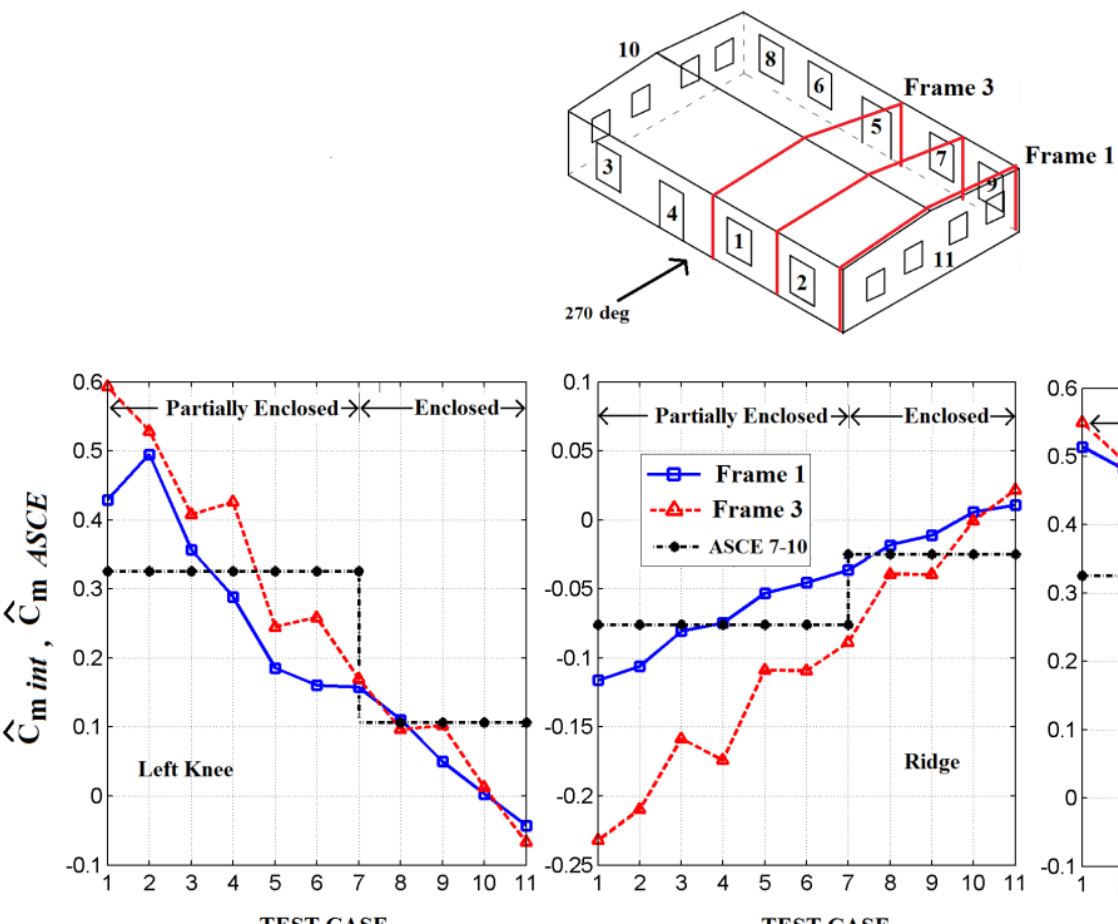

Figure $18 \hat{C}_{m}$ progressive failure experiment, WOW Model, $270 \mathrm{deg}$

ASCE 7-10 was observed to be unconservative in test cases $1-4$ (i.e. windward openings only), and near test case 8 (i.e. when area of windward openings is equal to the area of leeward openings).

Creation of more leeward and side openings was observed to further reduce the $\hat{C}_{m}$ int. This reinforces the previous statement (based on results of Figure 16 and Figure 17) that classifying buildings with equal sized dominant openings on windward and leeward sides under the same building enclosure category as no opening buildings (i.e. under enclosed building category) might lead to underestimation of internal pressures.

\section{Conclusions}

This paper presented results of an investigation conducted to quantify and understand the characteristics of net structural frame forces in low-rise buildings with single or multiple dominant openings. Frame internal forces were computed using Database-Assisted Design (DAD)

510 methodology. The pressure data used (external and internal) were obtained from the NIST database

511 for single dominant openings, and were collected experimentally at the WOW facility for multiple

512 dominant openings. 
The effect of internal pressure on frame forces was not only different for different frames (i.e., that

514 effect depended on the location of a frame in reference to the building openings), but also varied among different cross-sections of the same frame. The strength of that effect was highly dependent on the correlation between the forces induced by the external and internal pressures. For frame near an opening, mainly the cross-section on the windward side, internal pressure increased the net response by up to $65 \%$ and $45 \%$ in single and multiple openings, respectively. However, in frames located away from the openings, the internal pressure had milder effects on the critical net forces, and can even reduce the critical forces in some cross-opening cases. Generally high correlation coefficients, up to 0.67 and 0.48 for single and multiple dominant openings, respectively, can be observed between time histories of external and internal pressure induced frame forces.

A thorough comparison of frames forces evaluated using internal pressures obtained experimentally on the one hand and based on ASCE 7-10 provisions on the other was conducted. In this study, instead of the isolated internal pressures, their effective influence (i.e. accounting for the imperfect correlations between external and internal pressures) on net frame forces was used for comparison. The results showed that frame forces based on ASCE 7-10's internal pressures produced highly unconservative results in buildings with single and multiple openings, particularly when the wind direction was normal to the building openings. More importantly, it was also observed that defining a low-rise building with openings of equal sizes on the windward and leeward sides as "enclosed," based on the ASCE 7-10 provisions, can result in unconservative estimates. For buildings with single dominant openings, a reduction factor (for the highest net frame force), to account for the lack of perfect correlation between the external and internal pressures was computed as 0.85 , in contrast to the approximate reduction factor of 0.68 used in the ASCE 7-10. $G C_{p i}$ values of \pm 1.0 produced conservative results for buildings with a single dominant opening. The results also showed that, for buildings with multiple dominant equal sized cross openings (i.e. equal sized openings on the windward and leeward sides) $G C_{p i}$ value of \pm 0.42 produced in most cases moderately conservative results. The use of the ASCE 7-10 values of \pm 0.18 was found to be unconservative in 
most cases. It is therefore proposed that the enclosure classification of such buildings be changed

540 from enclosed buildings and $G C_{p i}$ values of \pm 0.42 be used instead of \pm 0.18 .

541

542

543

544

\section{Acknowledgments}

The authors acknowledge the support of the National Science Foundation (NSF Award No. 1234004) and appreciate the help of the Wall of Wind research engineers. Helpful comments by Dr.

Emil Simiu are gratefully acknowledged. Filmon Habte gratefully acknowledges the scholarship support provided by the Presidential Fellowship (Florida International University, Graduate School). The findings expressed in this paper are those of the authors only and do not necessarily represent the views of the sponsors.

\section{References}

[1] Holmes JD, Ginger JD. Internal pressures - The dominant windward opening case - A review. J Wind Eng Ind Aerodyn 2012;100:70-6. doi:10.1016/j.jweia.2011.11.005.

[2] Holmes JD. Wind loading of structures. CRC Press; 2015.

[3] Mehta KC, Yeatts BB, Smith DA. Analysis of wind-induced roof pressure data acquired in the field. Proc. Third Asia-Pac. Symp. Wind Eng., Hong Kong: 1993, p. 693-8.

[4] Beste F, Cermak JE. Correlation of internal and area-averaged external wind pressures on lowrise buildings. Proc 3rd Int Colloqium Bluff Body Aerodyn Appl 1997;69-71:557-66. doi:10.1016/S0167-6105(97)00186-4.

[5] Ginger JD, Letchford CW. Net pressures on a low-rise full-scale building. J Wind Eng Ind Aerodyn 1999;83:239-50. doi:10.1016/S0167-6105(99)00075-6.

[6] Sharma RN, Richards PJ. Net pressures on the roof of a low-rise building with wall openings. J Wind Eng Ind Aerodyn 2005;93:267-91. doi:10.1016/j.jweia.2005.01.001.

[7] Oh JH, Kopp GA, Inculet DR. The UWO contribution to the NIST aerodynamic database for wind loads on low buildings: Part 3. Internal pressures. J Wind Eng Ind Aerodyn 2007;95:75579.

[8] Karava P, Stathopoulos T. Wind-induced internal pressures in buildings with large façade openings. J Eng Mech 2011;138:358-70.

[9] Main JA, Fritz WP. Database-assisted design for wind: concepts, software, and examples for rigid and flexible buildings. National Institute of Standards and Technology, Technology Administration, US Department of Commerce; 2006.

[10] ASCE 7-10. Minimum design loads for building and other structures. American Society of Civil Engineers, Reston, VA; 2010.

[11] Holmes JD. Mean and fluctuating internal pressures induced by wind. Department of Civil and Systems Engineering, James Cook University of North Queensland; 1978.

[12] Vickery BJ. Gust-factors for internal-pressures in low rise buildings. J Wind Eng Ind Aerodyn 1986;23:259-71.

[13] Ho TCE, Surry D, Morrish D. NIST/TTU Cooperative Agreement-Windstorm Mitigation Initiative: Wind Tunnel Experiments on Generic Low Buildings. Tech. Rep. BLWT-SS20-2003, The Boundary Layer Wind Tunnel Laboratory, The University of Western Ontario, London, Ontario, Canada; 2003.

[14] Ho TCE, Surry D, Nywening M. NIST/TTU cooperative agreement-windstorm mitigation initiative: further experiments on generic low buildings. BLWTSS21-2003 Phase 2003;2. 
[15] Irwin PA. The role of wind tunnel modeling in the prediction of wind effects on bridges. Bridge Aerodyn 1998:59-85.

[16] Irwin PA. Wind engineering research needs, building codes and project specific studies. 11th Am. Conf. Wind Eng., 2009.

[17] Richards PJ, Hoxey RP, Connell BD, Lander DP. Wind-tunnel modelling of the Silsoe Cube. J Wind Eng Ind Aerodyn 2007;95:1384-99.

[18] Banks D. Measuring peak wind loads on solar power assemblies. 13th Int. Conf. Wind Eng., 2011.

[19] Tieleman HW. Wind tunnel simulation of wind loading on low-rise structures: a review. J Wind Eng Ind Aerodyn 2003;91:1627-49.

[20] Suresh Kumar K, Stathopoulos T. Spectral density function of wind pressures on various low building roof geometries. Wind Struct 1998;1:203.

[21] Asghari Mooneghi M, Irwin P, Chowdhury AG. Partial Turbulence Simulation Method for Small Structures. 14th Int. Conf. Wind Eng., Porto Alegre, Brazil: 2015.

[22] Sharma RN, Mason S, Driver P. Scaling methods for wind tunnel modelling of building internal pressures induced through openings 2010.

[23] Ginger JD, Mehta KC, Yeatts BB. Internal pressures in a low-rise full-scale building. J Wind Eng Ind Aerodyn 1997;72:163-74.

[24] Holmes JD. Discussion of: "Net pressures on the roof of a low-rise building with wall openings" by R.N. Sharma and P.J. Richards, J. Wind Eng. \& Ind. Aerodyn. Vol. 93, pp. 267-291, 2005. J Wind Eng Ind Aerodyn 2009;97:320-1. doi:10.1016/j.jweia.2009.08.001.

[25] Woods AR, Blackmore PA. The effect of dominant openings and porosity on internal pressures. Proc First IAWE Eur Afr Reg Conf 1995;57:167-77. doi:10.1016/0167-6105(95)00003-A.

[26] Irwin H, Cooper KR, Girard R. Correction of distortion effects caused by tubing systems in measurements of fluctuating pressures. J Wind Eng Ind Aerodyn 1979;5:93-107.

[27] Whalen TM, Sadek F, Simiu E. Database-assisted design for wind: basic concepts and software development. J Wind Eng Ind Aerodyn 2002;90:1349-68.

[28] Simiu E, Sadek F, Whalen TM, Jang S, Lu L-W, Diniz S, et al. Achieving safer and more economical buildings through database-assisted, reliability-based design for wind. J Wind Eng Ind Aerodyn 2003;91:1587-611.

[29] Rigato A, Chang P, Simiu E. Database-Assisted Design, Standardization, and Wind Direction Effects. J Struct Eng 2001;127:855-60.

[30] Jang S, Lu L-W, Sadek F, Simiu E. Database-assisted wind load capacity estimates for low-rise steel frames. J Struct Eng 2002;128:1594-603.

[31] Mensah AF, Datin PL, Prevatt DO, Gupta R, Van de Lindt JW. Database-assisted design methodology to predict wind-induced structural behavior of a light-framed wood building. Eng Struct 2011;33:674-84.

[32] Habte F, Chowdhury AG, Yeo D, Simiu E. Wind Directionality Factors for Nonhurricane and Hurricane-Prone Regions. J Struct Eng 2015;141:04014208.

[33] Habte F, Chowdhury AG, Yeo D, Simiu E. Design of rigid structures for wind using time series of demand-to-capacity indexes: Application to steel portal frames. Engineering Structures 2017; 132: 428-442.

[34] Sadek F, Simiu E. Peak non-Gaussian wind effects for database-assisted low-rise building design. J Eng Mech 2002;128:530-9.

[35] Mooneghi, M. A., Irwin, P., \& Chowdhury, A. G. (2016). Partial turbulence simulation method for predicting peak wind loads on small structures and building appurtenances. Journal of Wind Engineering and Industrial Aerodynamics 2016: 157, 47-62.

[36] Habte F, Chowdhury AG. Experimental Investigation of Wind-Induced Torsional Loads on a Low-Rise Building. Struct. Congr. 2015, ASCE; 2015, p. 2655-66.

[37] St Pierre LM, Kopp GA, Surry D, Ho TCE. The UWO contribution to the NIST aerodynamic database for wind loads on low buildings: Part 2. Comparison of data with wind load provisions. J Wind Eng Ind Aerodyn 2005;93:31-59. 
633

634

635

636

637

638

639

[38] Kopp GA, Oh JH, Inculet DR. Wind-induced internal pressures in houses. J Struct Eng 2008;134:1129-38.

[39] Pan F, Cai CS, Zhang W. Wind-induced internal pressures of buildings with multiple openings. J Eng Mech 2012;139:376-85.

[40] Tecle AS, Bitsuamlak GT, ALY AM. Internal pressure in a low-rise building with existing envelope openings and sudden breaching. Wind Struct 2013;16:25-46. 